\title{
Article \\ Component-Oriented Modeling of a Micro-Scale Organic Rankine Cycle System for Waste Heat Recovery Applications
}

\author{
Ramin Moradi $^{1}$, Emanuele Habib ${ }^{1}\left(\mathbb{D}\right.$, Enrico Bocci ${ }^{2}(\mathbb{D})$ and Luca Cioccolanti $^{3, *}(\mathbb{D})$ \\ 1 DIAEE, Sapienza Università di Roma, via Eudossiana 18, 00184 Rome, Italy; \\ ramin.moradi@uniroma1.it (R.M.); emanuele.habib@uniroma1.it (E.H.) \\ 2 Department of Engineering Sciences, Marconi University, via Paolo Emilio 29, 00193 Rome, Italy; \\ e.bocci@unimarconi.it \\ 3 CREAT, Università eCampus, via Isimbardi 10, 22060 Novedrate, Italy \\ * Correspondence: luca.cioccolanti@uniecampus.it
}

Citation: Moradi, R.; Habib, E.;

Bocci, E.; Cioccolanti, L.

Component-Oriented Modeling of a Micro-Scale Organic Rankine Cycle System for Waste Heat Recovery Applications. Appl. Sci. 2021, 11, 1984. https://doi.org/10.3390/ app11051984

Academic Editor: Andrea Baccioli

Received: 4 February 2021

Accepted: 20 February 2021

Published: 24 February 2021

Publisher's Note: MDPI stays neutral with regard to jurisdictional claims in published maps and institutional affiliations.

Copyright: (c) 2021 by the authors. Licensee MDPI, Basel, Switzerland. This article is an open access article distributed under the terms and conditions of the Creative Commons Attribution (CC BY) license (https:// creativecommons.org/licenses/by/ $4.0 /)$.
Featured Application: The waste heat from industrial processes or energy conversion systems may vary appreciably with time. The proposed numerical model aims at assessing the per-formance of a small-scale organic Rankine cycle system in off-design operating conditions, which may occur in the case of low-grade waste heat recovery.

Abstract: Organic Rankine cycle (ORC) systems are some of the most suitable technologies to produce electricity from low-temperature waste heat. In this study, a non-regenerative, micro-scale ORC system was tested in off-design conditions using R134a as the working fluid. The experimental data were then used to tune the semi-empirical models of the main components of the system. Eventually, the models were used in a component-oriented system solver to map the system electric performance at varying operating conditions. The analysis highlighted the non-negligible impact of the plunger pump on the system performance Indeed, the experimental results showed that the low pump efficiency in the investigated operating range can lead to negative net electric power in some working conditions. For most data points, the expander and the pump isentropic efficiencies are found in the approximate ranges of $35 \%$ to $55 \%$ and $17 \%$ to $34 \%$, respectively. Furthermore, the maximum net electric power was about $200 \mathrm{~W}$ with a net electric efficiency of about $1.2 \%$, thus also stressing the importance of a proper selection of the pump for waste heat recovery applications.

Keywords: micro-scale ORC; off-design performance; experimental modeling; volumetric pump modeling; low-grade waste heat recovery applications

\section{Introduction}

Waste heat recovery (WHR) has huge potential to increase the energy efficiency of industrial plants thus reducing their fossil fuel consumption and the related $\mathrm{CO}_{2}$ emissions. Indeed, many industrial processes reject heat at different temperatures, determining the quality of the waste heat as high $\left(>400{ }^{\circ} \mathrm{C}\right)$, medium $\left(100-400{ }^{\circ} \mathrm{C}\right)$, or low $\left(<100{ }^{\circ} \mathrm{C}\right)[1]$. In general, a WHR system may use the technically and economically usable part of this waste heat in different ways such as (i) direct use without upgrading, (ii) use after upgrading through heat pumps, and (iii) electricity production. In the case of low and medium grade waste heat, organic Rankine cycle (ORC) systems have attracted particular attention in recent years due to their reliability, flexibility, safety, and applicability for low-temperature power generation [2]. ORC systems have already been deployed at medium (50-300 kW) and large scales $(>300 \mathrm{~kW})$ by industries as a mature and reliable technology as reported in [3], yet several challenges must be faced at the micro $(<10 \mathrm{~kW})$ to small (10-50 kW) scales. At these scales, the systems' primary costs and low conversion efficiencies are still limiting their wider adoption. Moreover, the latter becomes significantly more visible in cases where the system operates in off-design conditions. The instability 
of the heat source is usually the main cause of the off-design conditions, which result in system efficiency degradation at best or pump cavitation or turbine damage at worst. In addition, the variations of the heat sink condition, the electric load instability, and the working fluid loss due to leakage are the other prominent causes of the system being in off-design conditions. Therefore, understanding the ORC system off-design characteristics is necessary to realize a system with reliable on-site performance that can be integrated with the other energy systems.

In the literature, an extensive number of papers can be found dealing with experimental studies of ORC systems. For instance, 68 references were used in an analysis published in 2018 on the experimental database of ORC systems [4]. Hence, only a non-exhaustive number of references dealing with subcritical ORC systems using R134a as the working fluid are reported hereunder.

Wang et al. [5] developed a test bench to investigate the performance of a scroll expander with a displacement of $6.8 \mathrm{~cm}^{3}$ using R134a. The expander maximum power and efficiency were about $1.17 \mathrm{~kW}$ and $70 \%$, respectively. A car scroll compressor was converted into an expander in an ORC system in [6] using R134a. The best performances of the system were reported as an efficiency of $3.3 \%$ and $279.58 \mathrm{~W}$ in the range of the heat source temperature of 75 to $95^{\circ} \mathrm{C}$. An air screw compressor was converted for use as an expander in a micro-scale ORC unit with R134a in [7]. Their test bench was a very-low-temperature WHR system with a heat source temperature range of 55 to $65^{\circ} \mathrm{C}$. The efficiency of their system was reported as $1.2 \%$ to $4.56 \%$. Dumont et al. [8] devised a heat pump/ORC system for building applications. In the ORC mode, their system could produce a maximum thermal efficiency of $4.2 \%$ and a gross power output of $3.7 \mathrm{~kW}$ using the scroll expander and R134a as the working fluid.

In this study, a non-regenerative ORC unit was tested using R134a in off-design conditions. The system consists of an open-drive, lubricated scroll expander; a plunger pump; and two plate heat exchangers as the evaporator and the condenser. In addition to the experimental performance of the ORC system and its main performance, experimental data were used to simulate the components of the system. The main novelties of the numerical investigation rely on:

- Experimental study of a micro-scale ORC system with the scroll expander shaft speed considerably lower than typical values due to the electric generator requirements.

- Presenting a new semi-empirical model for the plunger pump's volumetric, isentropic, and electromechanical efficiency.

- Adopting the improved semi-empirical model of the scroll expander developed by some authors in this work using system-level modeling.

Moreover, this study is among the few research works showing the non-negligible impact of the pump on the performance of a micro-ORC unit. The empirical models of the pump show good accuracy compared to the experimental data that can be tuned for similar pumps. Finally, the limitations of the test bench performance are presented.

\section{Experimental Setup and Procedure}

The ORC unit is a non-regenerative system consisted of a plunger pump, two plate heat exchangers (PHEs), a scroll expander, and a liquid receiver charged with R134a. The heat source is provided by five electrical heaters heating the diathermic oil, and the heat sink is cooled down by a chiller with water as the cooling medium. The organic fluid and the diathermic oil flow rates are adjusted using pump inverters, while the water flow rate provided by the chiller pump is fixed in all measurements. A photo of the ORC system studied in this work, its process and instrument diagram (P\&ID) and the temperatureentropy (T-S) diagram for a given operating condition during the experimental tests are shown in Figure 1. 
(a)
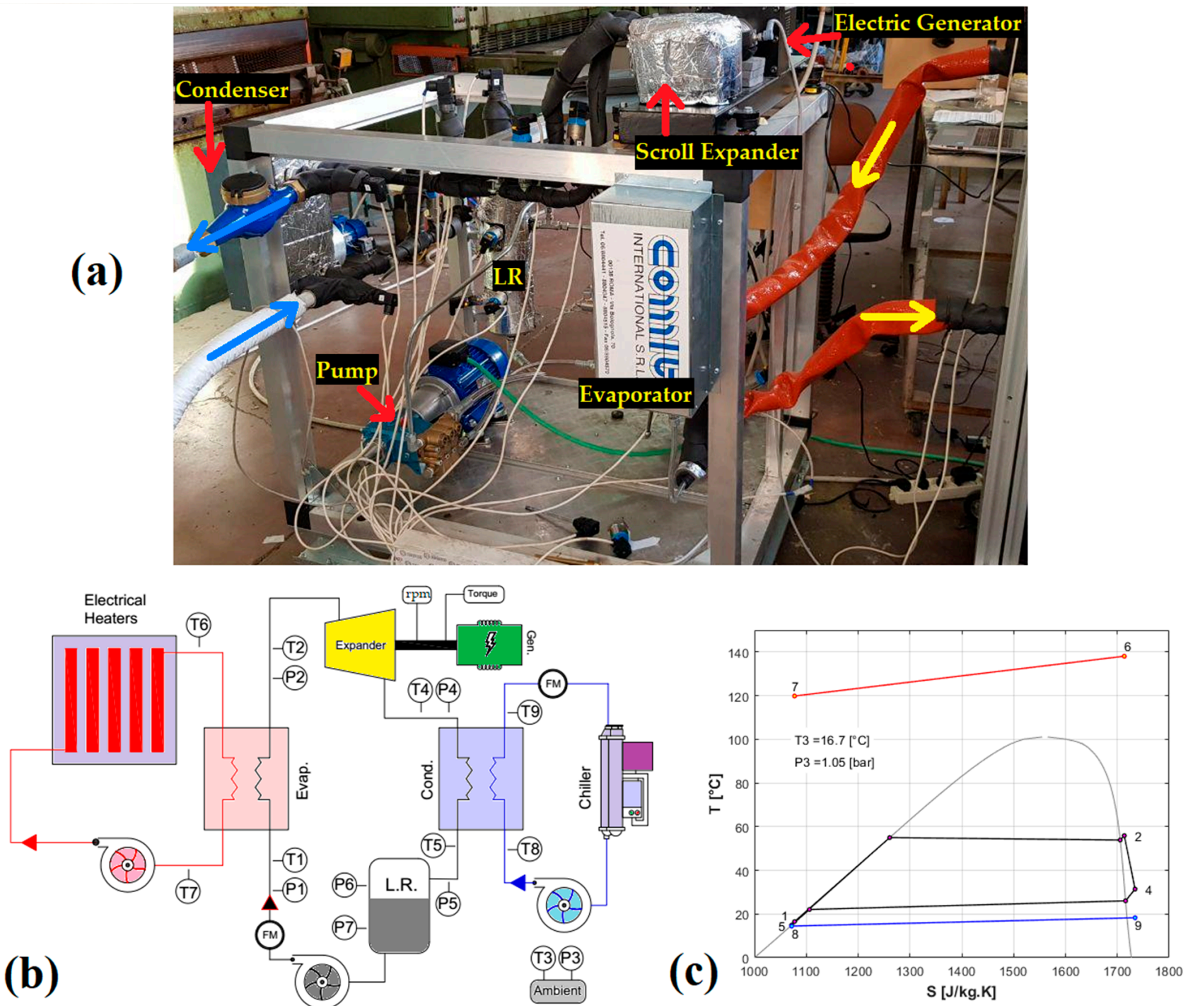

Figure 1. The photo of the organic Rankine cycle (ORC) test bench (a), the system schematic (b), and the temperature-entropy (T-S) diagram for a given operating condition during the tests (c).

The measured data of the steady-state performance were recorded with a time interval of $1 \mathrm{~s}$ for $10 \mathrm{~min}$ (600 data points), and then the average of the recorded data was used. To determine whether the system was at a steady-state condition, the methodology proposed by Woodland et al. [9] and also used by Ziviani et al. [10] was applied. More precisely, the average of the first 30 data points was compared with the average of the last 30 data points, meaning two sample data with a 9-min delay. If the average of the two groups shows a negligible deviation, the system is considered at steady-state.

Considering the characteristics of the test bench, 84 useful data points were recorded representing the off-design conditions of the system as far as the system boundaries and component limitations allowed. A description of the main components of the ORC test bench is reported in Table 1, and the characteristics of the sensors are given in Table 2. 
Table 1. Characteristics of main components of the ORC unit.

\begin{tabular}{|c|c|c|}
\hline & Density (at $20^{\circ} \mathrm{C}$ ) [kg/L] & 0.8851 \\
\hline \multirow{2}{*}{$\begin{array}{l}\text { Heat source medium } \\
\text { (Texatherm HT22) }\end{array}$} & Operating temperature range $\left[{ }^{\circ} \mathrm{C}\right]$ & $-45-290$ \\
\hline & Kinematic viscosity [cSt] & $\begin{array}{c}22 \text { at } 40^{\circ} \mathrm{C} \\
3.75 \text { at } 100^{\circ} \mathrm{C}\end{array}$ \\
\hline Electrical heaters (5 numbers) & Resistor power [kWel] & 4.5 \\
\hline \multirow{2}{*}{$\begin{array}{l}\text { Diathermic oil pump } \\
\quad \text { (gear pump) }\end{array}$} & Maximum flow rate [lpm] & 23.5 \\
\hline & Maximum motor speed [rpm] & 1400 \\
\hline \multirow{4}{*}{ Evaporator/condenser } & Number of plates & $50 / 60$ \\
\hline & Dimension $\left(\mathrm{L}^{*} \mathrm{~W}\right)\left[\mathrm{mm}^{2}\right]$ & $304^{*} 124$ \\
\hline & Heat transfer area of one plate $\left[\mathrm{m}^{2}\right]$ & 0.03 \\
\hline & Space between two plates [mm] & 2.4 \\
\hline \multirow{3}{*}{$\begin{array}{l}\text { Organic fluid pump } \\
\text { (piston pump) }\end{array}$} & Maximum flow rate [lpm] & 13.26 \\
\hline & Maximum motor speed [rpm] & 1430 \\
\hline & Nominal efficiency [\%] & 85 \\
\hline \multirow{6}{*}{ Scroll compressor } & Model & Sanden TRS090 \\
\hline & Nominal fluid & R134a \\
\hline & Swept volume [cc/rev] & 85.7 \\
\hline & BVR $[-]$ & 1.9 \\
\hline & Oil charge $(\mathrm{PAG})[\mathrm{cc}]$ & $130+20$ \\
\hline & Maximum continuous speed [rpm] & 10,000 \\
\hline \multirow{4}{*}{$\begin{array}{c}\text { Electric generator } \\
\text { (3-phase brushless servomotor) }\end{array}$} & Nominal speed [rpm] & 1500 \\
\hline & Nominal power [kW] & 1.59 \\
\hline & Nominal Voltage [V] & 334 \\
\hline & Maximum torque [N.m] & 10 \\
\hline \multirow{2}{*}{ Liquid receiver } & Internal Volume [L] & 3 \\
\hline & Maximum pressure [bar] & 22.5 \\
\hline
\end{tabular}

Table 2. Characteristics of the sensors of the ORC system.

\begin{tabular}{|c|c|c|c|c|}
\hline Parameter & Model & Resolution & Accuracy & Output Signal \\
\hline Temperature & PT100 resistance & $0.1^{\circ} \mathrm{C}$ & $\pm(0.15+0.002 * \mathrm{~T})\left[{ }^{\circ} \mathrm{C}\right]$ & $4-20 \mathrm{~mA}$ \\
\hline Pressure & $\begin{array}{l}\text { PMC131(A11E1A2T } \\
\text { \& A11E1A2R) }\end{array}$ & 2 mbar & $\begin{array}{c}<0.5 \% \text { of sensor } \\
\text { upper limit }\end{array}$ & $4-20 \mathrm{~mA}$ \\
\hline Flow rate & $\begin{array}{c}\text { Gear flow meter, } \\
\text { Cobold, } \\
\text { DOM-S15HR31 }\end{array}$ & 702 pulse/L & $1 \%$ of the read value & $4-20 \mathrm{~mA}$ \\
\hline Torque & DataFlex 16/30 & 360 pulse/rev & $0.1 \%$ of the read value & -10 to $+10 \mathrm{~V}$ \\
\hline Shaft speed & DataFlex 16/30 & 360 pulse/rev & $1 \mathrm{deg}$ & 0-10 V \\
\hline
\end{tabular}

The following points are noteworthy regarding the experimental procedure and the subsequent database:

- The operation of the system was adjusted by varying the rotational speed of the refrigerant and hot fluid pump, the hot and cold fluid inlet temperatures to the evaporator and condenser, respectively; and the electric load, hence a total of five degrees of freedom;

- The electric power consumption of the organic fluid pump and the electric power produced by the generator were measured using electric data loggers;

- The water flow rate was measured with a pulse flow meter, and an average value of 10 measurements was used for each data set.

- The hot fluid flow rate was indirectly calculated considering the hot fluid pump specifications and applying an empirical model available from the literature. 
- The scroll expander always works in off-design conditions compared to the typical shaft speeds commonly reported in the literature due to the limited rotational speed of the electric generator.

- To better illuminate the experimental constraints, the following aspects are noteworthy too:

- The maximum pressure was limited due to the pressure sensors that can measure up to 16 bar. The scroll expander nominal working pressure was around 14 bar and could not be extended much;

- Two pressure sensors were installed on the liquid receiver body to measure the liquid level. Their maximum threshold was 6 bar;

- The maximum thermal power was limited to around $22.5 \mathrm{~kW}$ using five electric heaters. However, the experimental data showed that around $20 \%$ of the available thermal power is wasted during the heat transfer from the resistors to the diathermic oil;

- The maximum refrigerant flow rate was limited due to the maximum pressure of the cycle;

- The maximum scroll expander speed was limited firstly due to the electric generator that can work at a maximum of $1500 \mathrm{rpm}$. It was also limited by the refrigerant flow rate delivered to the expander, which in turn was limited due to the maximum pressure of the system as described in the point above.

- The water flow rate was fixed because the chiller turns off if the flow rate is reduced. Therefore, the subcooling degree could not be adjusted at the condenser outlet using the water flow rate; instead, it was affected by the initial mass charge of the system.

\section{Experimental Results}

The ORC system and its performances are outlined in this section using the raw experimental data. The recorded data were post-processed in $\mathrm{MATLAB}^{\odot}$ using the pure refrigerant properties adopted from CoolProp ad-hoc. The diathermic oil thermophysical properties were calculated using the table provided by the supplier and are correlated and presented in the equations in Appendix A. The range of the important parameters of the experimental data is presented in Table 3.

Table 3. Range of working conditions during the experimental tests campaign.

\begin{tabular}{|c|c|c|c|c|c|c|c|}
\hline$\dot{m}_{r e f}[\mathrm{~kg} / \mathrm{h}]$ & $N_{\text {exp }}[\mathrm{rpm}]$ & $P_{\text {su,exp }}[\mathrm{bar}]$ & $P_{s u, p}[$ bar] & $T_{i n, H F, e v}\left[{ }^{\circ} \mathrm{C}\right]$ & $T_{i n_{, \prime} C F c d}\left[{ }^{\circ} \mathrm{C}\right]$ & SH [K] & $\mathrm{SC}[\mathrm{K}]$ \\
\hline 195-176 & 753-1416 & $11.2-15.4$ & $4.7-7.1$ & $119.7-150.7$ & $8.7-19.6$ & $2-24$ & $3.7-7.9$ \\
\hline
\end{tabular}

\subsection{Data Reduction}

The performance of the ORC system and its main components is expressed in common and relevant parameters of such systems. The theoretical mass flow rate of the volumetric pumps was calculated using Equation (1). This equation was used to calculate the theoretical mass flow rate of the diathermic oil and the refrigerant in the evaporator.

$$
\dot{m}_{t h, i}=\frac{N_{i} \cdot S V_{i} \cdot \rho_{s u, i}}{60}
$$

where $N$ is the pump speed (rpm), $S V$ is the pump swept volume ( $\left.\mathrm{m}^{3} / \mathrm{rev}\right)$ and $\rho_{i}$ is the fluid density $\left(\mathrm{kg} / \mathrm{m}^{3}\right)$.

However, the real flow rate of the volumetric pumps is always less than their theoretical flow rates due to internal leakage. Hence, the volumetric efficiency of a pump depends on the working conditions of the pump, especially its rotational speed and operating temperature. The latter affects the fluid viscosity and the physical condition of the internal 
sealings. The ratio of the pump measured mass flow rate over the theoretical mass flow rate is the pump volumetric efficiency.

$$
\eta_{v o l, p}=\frac{\dot{m}_{m e a s}}{\dot{m}_{t h}}
$$

Expander isentropic and mechanical efficiencies are presented in Equations (3) and (4), respectively.

$$
\begin{gathered}
\eta_{\text {is,exp }}=\frac{\dot{W}_{\text {th,act }}}{\dot{W}_{t h, i s}} \times 100=\frac{h_{\text {su,exp }}-h_{\text {dis,exp }}}{h_{\text {su,exp }}-h_{\text {dis, is,exp }}} \times 100 \\
\eta_{\text {mech,exp }}=\frac{\dot{W}_{s h}}{\dot{W}_{t h, a c t}} \times 100=\frac{\dot{W}_{s h}}{\dot{m}\left(h_{\text {su,exp }}-h_{\text {dis,exp }}\right)} \times 100
\end{gathered}
$$

The expander produced shaft power was calculated using Equation (5).

$$
\dot{W}_{s h}=2 \pi \tau \cdot N_{\text {exp }} / 60
$$

The scroll expander volumetric efficiency also called the filling factor, is the ratio of the measured volumetric flow rate over the theoretical volumetric flow rate. Unlike the pump efficiency, its value is usually above unity indicating internal leakage.

$$
F F_{\text {exp }}=\frac{\dot{V}_{\text {meas }}}{\dot{V}_{\text {th }}}=\frac{\dot{m}_{r e f} / \rho_{\text {su,exp }}}{N_{\text {exp }} \cdot S V_{\text {comp }} /(60 B V R)}
$$

where $B V R$ is the expander built-in volume ratio adopted from the manufacturer datasheet to calculate the expander swept volume using the scroll compressor suction displacement $\left(S V_{\text {comp }}\right)$. Finally, the system performance is expressed using the net and gross electric efficiencies:

$$
\begin{aligned}
& \eta_{e l, n e t}=\frac{\dot{W}_{e l, n e t}}{\dot{Q}_{e v}} \times 100=\frac{\dot{W}_{e l, e x p}-\dot{W}_{e l, p}}{\dot{m}\left(h_{e x, e v, H F}-h_{i n . e v, H F}\right)} \times 100 \\
& \eta_{e l, g r o s s}=\frac{\dot{W}_{e l, e x p}}{\dot{Q}_{e v}} \times 100=\frac{\dot{W}_{e l, e x p}}{\dot{m}\left(h_{e x, e v, H F}-h_{i n, e v, H F}\right)} \times 100
\end{aligned}
$$

The gross efficiency is also used here since the refrigerant pump selected for the tests operates in off-design conditions resulting in low isentropic efficiencies, which leads to negative net electric efficiency for some points. To better understand the impact of the pump, the back-work ratio (BWR) is presented as follows:

$$
B W R=\frac{\dot{W}_{e l, p}}{\dot{W}_{e l, \exp }}
$$

\subsection{Experimental Data}

The tests were performed in different working conditions to provide adequate data points for evaluation of the off-design performance of the system. To this end, the system was run at different flow rates as far as the system boundaries were met. The top boundary represents whether the available power in the evaporator insufficient to superheat the working fluid or the electric generator's maximum rotation speed is reached. The low boundaries are related to a minimum superheating degree of $2 \mathrm{~K}$ and the low electric power produced at low flow rates, which is below the minimum electric load, thus causing unstable operation of the system. Instead of creating a matrix of the experiments, which would make the work exhaustive and time-consuming, the data were taken for each heat source and sink conditions such that the system boundaries were met and thus most 
possible working conditions were tested. Figure 2 presents some important parameters of the experimental data representing the range of the experimental database.
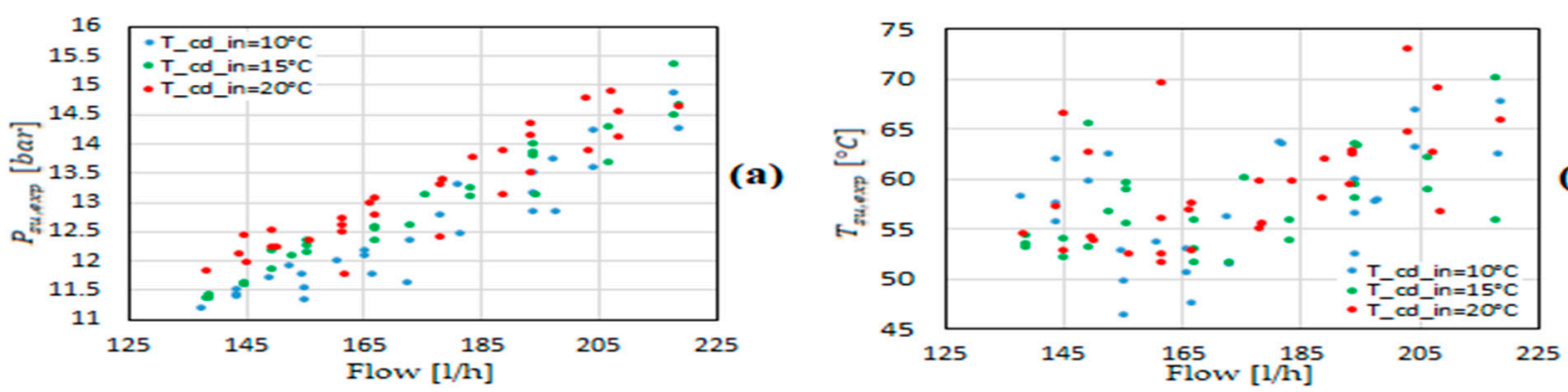

(b)
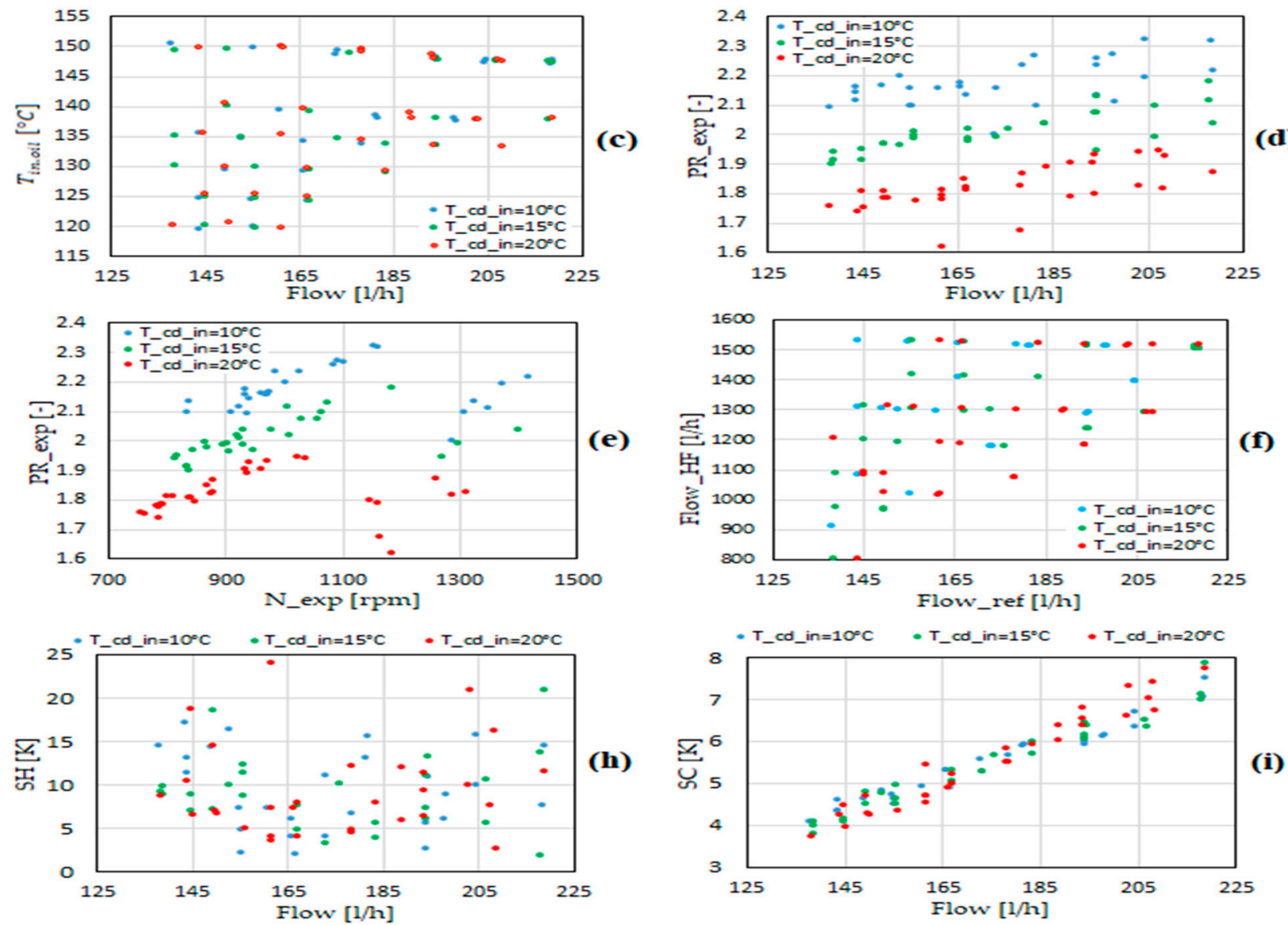

Figure 2. Range of the parameters constituting the experimental database: expander suction pressure vs flow rate (a), expander suction temperature vs flow rate $(\mathbf{b})$, hot fluid inlet temperature to the evaporator vs flow rate (c), expander pressure ratio vs flow rate (d), expander pressure ratio vs expander shaft speed (e), hot fluid flow rate vs refrigerant flow rate in the evaporator (f), superheating degree vs refrigerant flow rate in the evaporator (h), and subcooling degree vs. refrigerant flow rate in the condenser (i).

\subsection{The Refrigerant Pump}

The use of the plunger pump in the micro-scale ORC test bench is a double-edged sword. In the steam Rankine cycle, the power consumption of the pump is negligible compared to the power produced by the turbine and can be neglected in the calculation of the net system power [11]. Despite its importance, the real pump performances in the ORC system were reported in relatively few studies in the literature, as shown in Figure 3. It can be concluded from Figure 3 that the average efficiency of $35 \%$ is reasonable for pumps in ORC systems unlike numerical studies or engine design, in which the pump efficiency is taken as $65-85 \%$ [12]. The low pump performance is more critical in micro-scale ORC 
systems as even negative net power was reported by Yamada et al. [13]. The negative net power was observed in the experiments in this work as well.

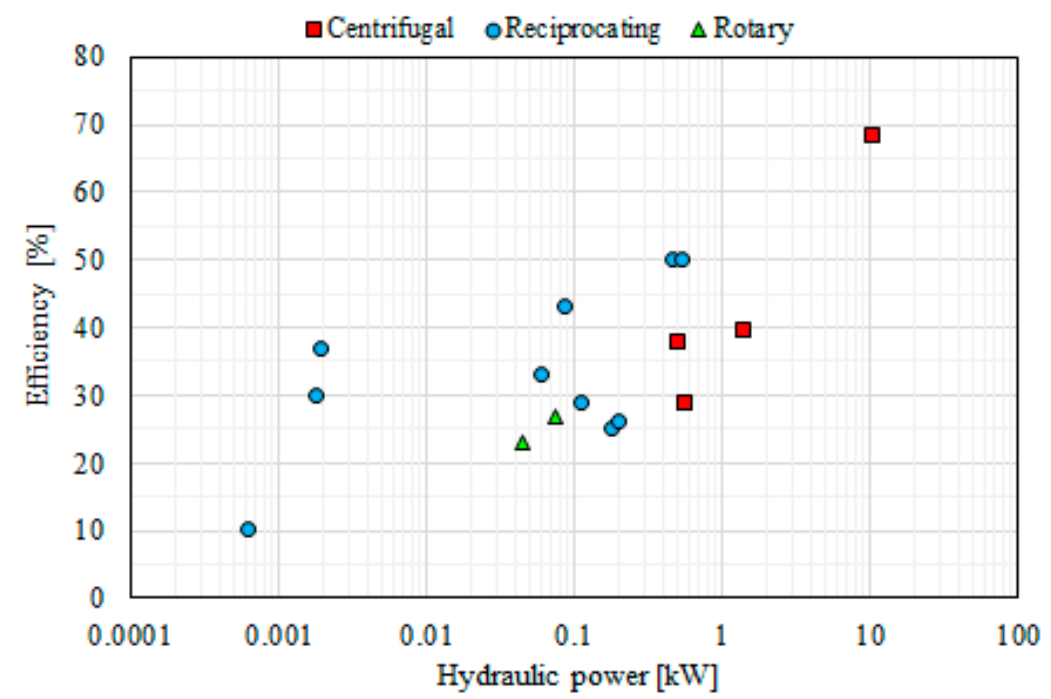

Figure 3. Reported pump maximum efficiency and hydraulic power in the literature up to 2017 based on data from [11].

The advantage of the selected pump in this work is its ability to provide a wide range of pressure and flow rate, facilitating the study of the expander machine in its off-design conditions. However, considering the maximum pressure of the system, these conditions lead to a significant drop in its isentropic efficiency and the net system efficiency accordingly.

This effect is observed in the experiments in this work as shown in Figure 4, in which the calculated isentropic efficiency of the pump is considerably lower than the nominal value of $85 \%$ stated by the manufacturer.
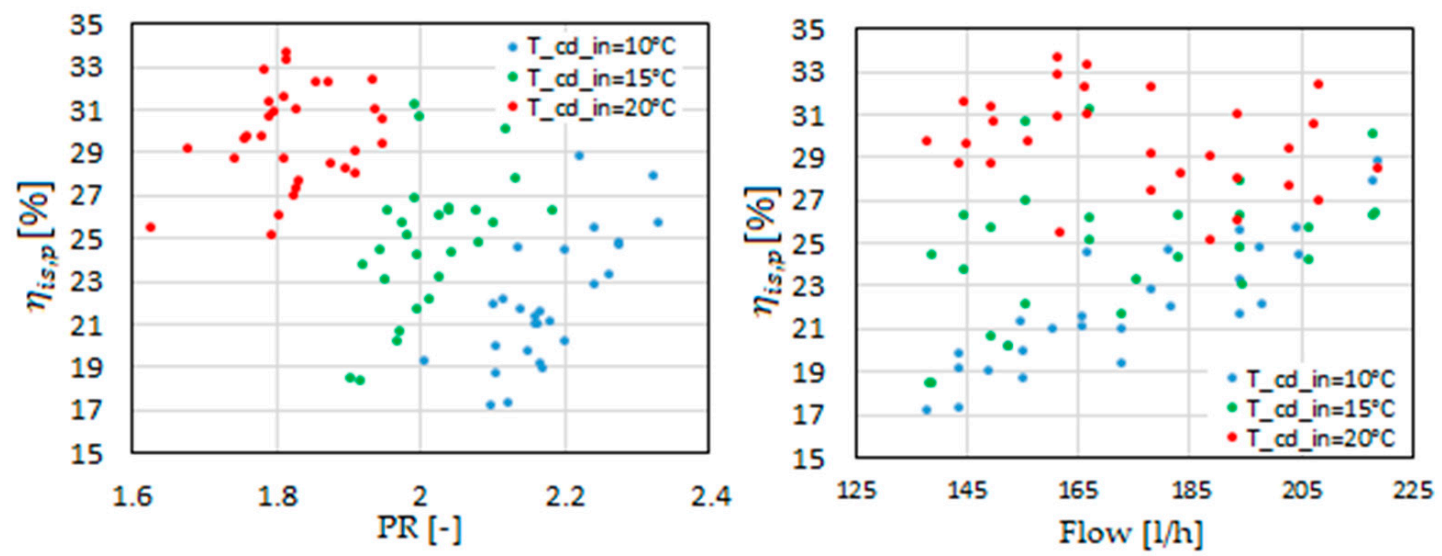

Figure 4. The refrigerant pump isentropic efficiency with pressure ratio (PR) (left), and with flow rate (right).

Instead, the pump volumetric efficiency shows high values as presented in Figure 5. Despite being penalized in higher flow rates (and therefore higher rotational speeds) due to an increment in the internal leakage, the good volumetric efficiency shows the high quality of the pump sealings during the tests. 


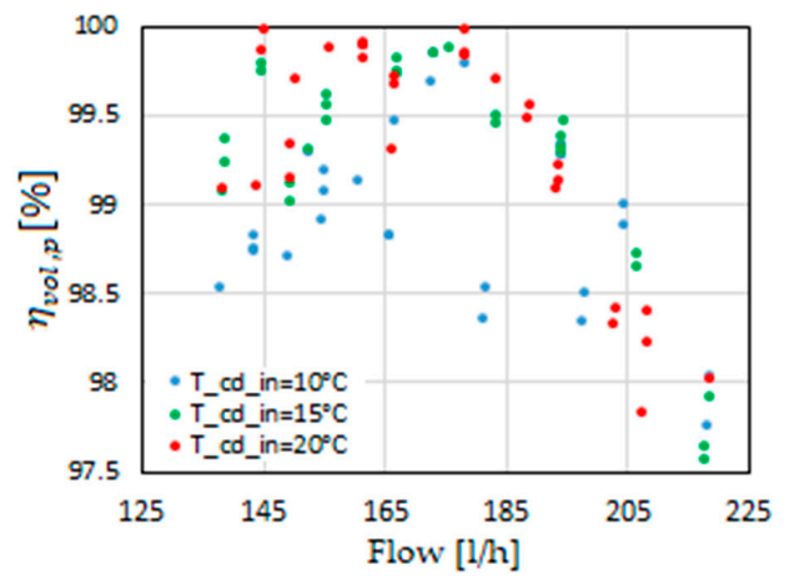

Figure 5. Refrigerant pump volumetric efficiency with the flow rate.

\subsection{Scroll Expander}

The isentropic efficiency of the scroll expander is shown in Figure 6. Most data are in the range of $40 \%$ to $55 \%$ in the range of the pressure ratio around the expander BVR. Therefore, the under-expansion and over-expansion losses may not affect the isentropic efficiency much. However, the isentropic efficiency is slightly reduced in higher expander rotational speeds corresponding to higher pressure ratios, in which the under-expansion losses occur.
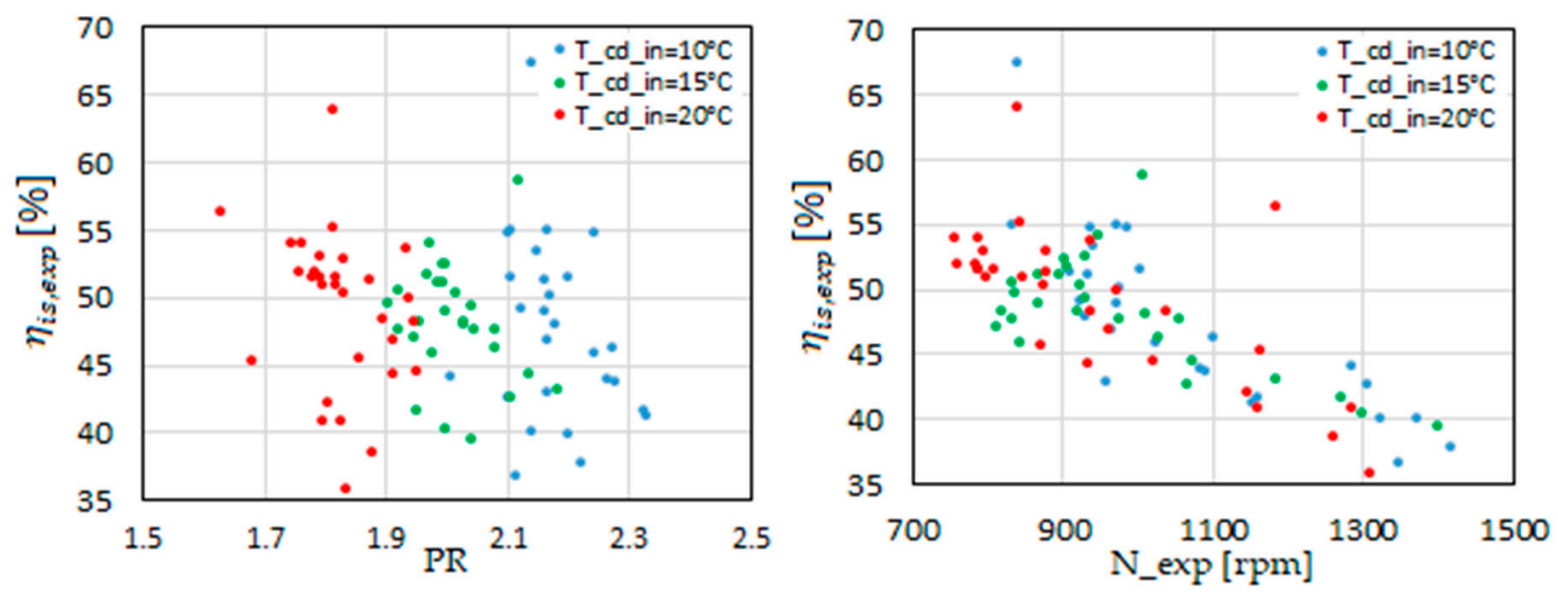

Figure 6. Scroll expander isentropic efficiency with pressure ratio (PR) (left), and with shaft speed (right).

The expander shaft power is presented in Figure 7, showing that the scroll expander produced up to a maximum of $450 \mathrm{~W}$ approximately in a range of relatively low shaft speeds. Higher shaft power is produced at higher shaft speeds, while the isentropic efficiency is penalized as mentioned. In addition, the shaft power increases slightly in higher pressure ratios.

Similar to volumetric pumps, the volumetric efficiency of volumetric expanders is directly associated with the internal leakage. It is well-known that the filling factor $(F F)$ strongly depends on the expander rotational speed and weakly on the inlet pressure of the expander. As shown in Figure 8, the same is observed here. Relatively high values of the filling factor at low shaft speeds indicate significant leakage at these working conditions. 


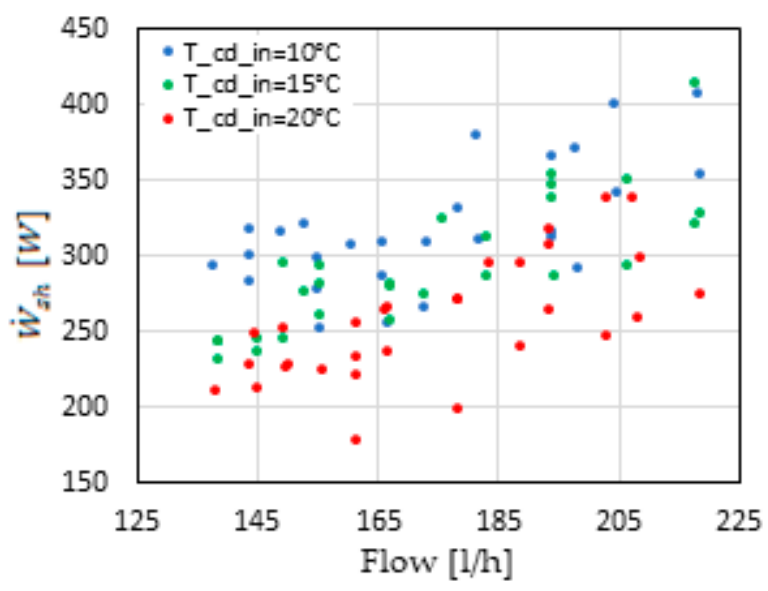

Figure 7. Scroll expander shaft power with flow rate.
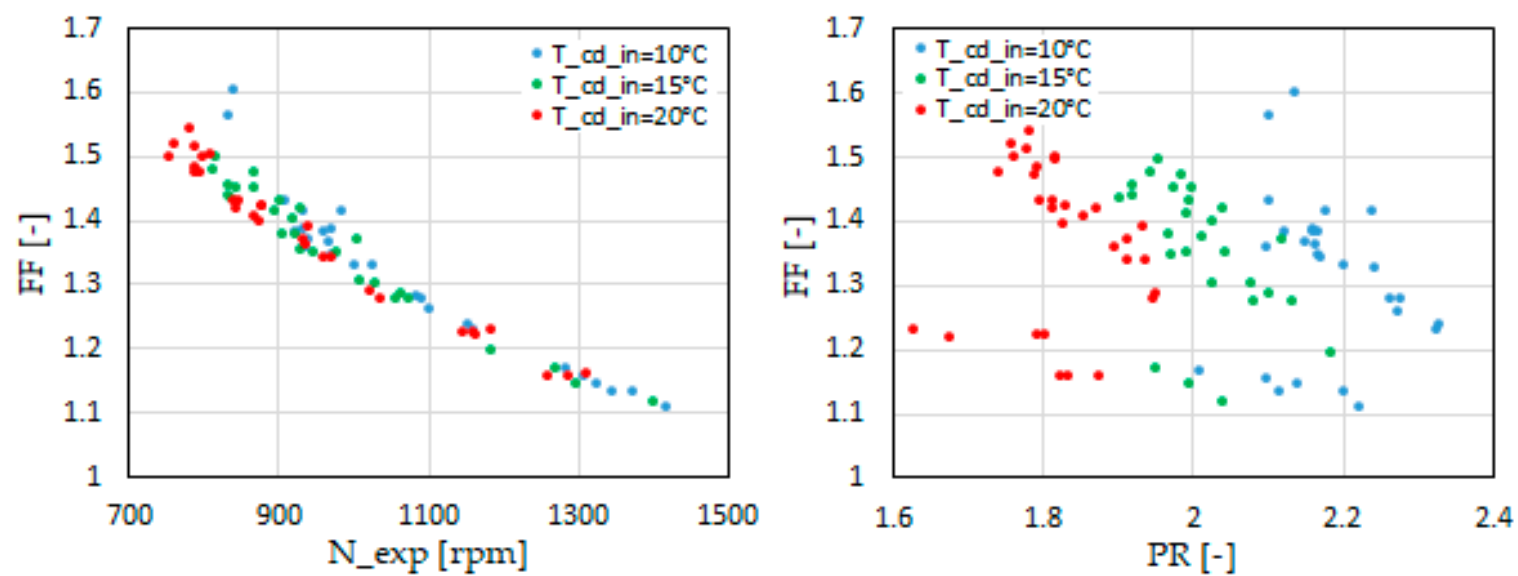

Figure 8. Scroll expander filling factor with shaft speed (left), and with pressure ratio (PR) (right).

In general, it is expected that the $F F$ is always higher than unity due to the inevitable internal leakage. Indeed, FF $<1$ means the measured flow rate is lower than the theoretical flow rate of the expander. However, it is unlikely that a volumetric expander produces power while its cambers are not filled by the gas. This effect was observed in several experimental studies on scroll expanders and is defined as "under-filling" of the suction chamber $[10,14]$. Nevertheless, the authors believe that $F F<1$ is because the suction density of the expander was calculated using the temperature and pressure measured at the expander suction pipe, while the real gas density that enters the expander chambers may differ considerably due to the pressure drop between the expander suction pipe and the suction port of the scroll revolute. Therefore, a conclusion of under-filling should be deduced with caution.

\subsection{System Performance}

The net electric efficiency and power of the ORC system are presented in Figure 9. The low and, in a few cases, even negative values are due to the low isentropic efficiency of the refrigerant pump working in off-design conditions as mentioned before. Indeed, the present test bench had been initially designed to study the performances of different expansion devices such as the scroll compressor of this study while the net efficiency of the system was not of concern. Thus, the pump was adopted considering its ability to generate a wide range of pressure and flow rates to supply the expander machines at different working conditions. 

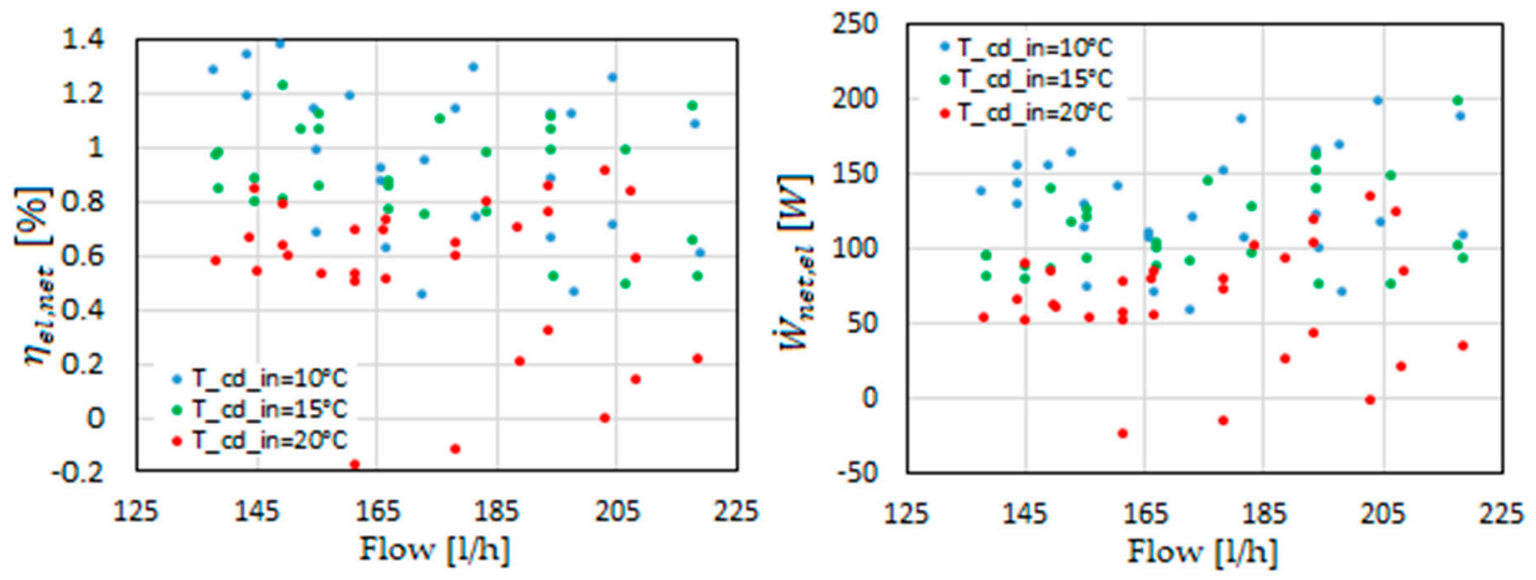

Figure 9. ORC system net electric efficiency (left), and net electric power with flow rate (right).

To better understand the destructive impact of the low isentropic efficiency of the pump on the net efficiency of the system, the back-work ratio (BWR) is presented in Figure 10 confirming the disproportionate pump selection for the range of the power generated by the ORC system. BWR increases as the heat source temperature and fluid critical temperature decrease [15]. Furthermore, BWR is estimated to be about four times higher for R134a compared to water [16].
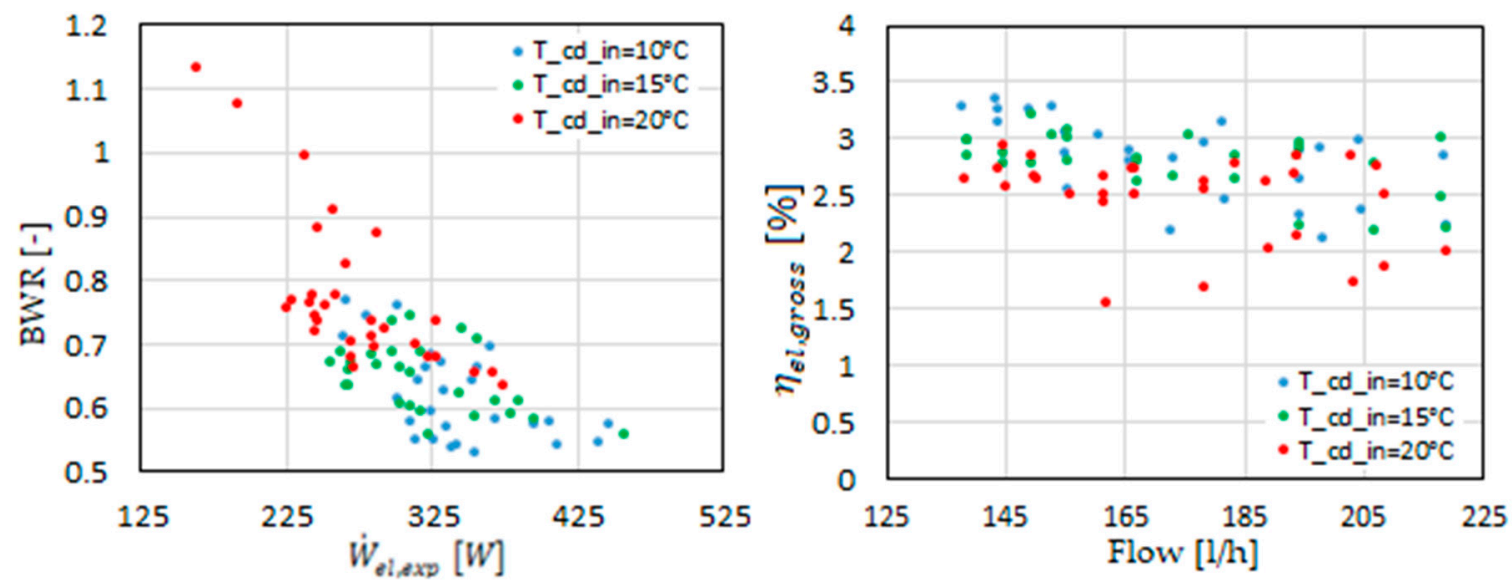

Figure 10. Pump back-work ratio (BWR) with expander produced electric power (left), and ORC system gross efficiency with flow rate (right).

Therefore, this parameter reveals the non-negligible impact of the pump power consumption in micro-to-small scale power systems for low-grade waste heat recovery. Hence, it is worth noting the gross system electric efficiency as well in Figure 10 to obtain an estimation of the net electric efficiency if a well-sized pump is used.

\section{Modeling of the System Components}

The different components of the ORC system are represented by semi-empirical models tuned using the experimental data obtained during the tests. Hence, it is possible to assess: (i) the volumetric efficiency of the hot fluid pump; (ii) the heat transfer in the plate heat exchangers (PHEs); (iii) the volumetric, isentropic, and electromechanical efficiencies of the refrigerant pump; (iv) and the scroll expander isentropic and volumetric efficiencies.

The system solver was developed in MATLAB ${ }^{\odot}$, and these models are referred to by the solver as functions. The solver is used to map the net electric performances of the system by changing the heat source temperature and the expander shaft speed when the other boundaries are fixed. 
The models are presented in the following, except for the model of the scroll expander that was discussed in detail by some authors of this work in [17]. The calculation of the uncertainties of the measurements was performed according to Appendix B.

\subsection{Oil Pump}

Since the flow rate of the diathermic oil in the evaporator was not measured during the experiments, evaluation of its values was performed using the empirical models adapted from the literature. Regarding the gear pump in the hot circuit, the volumetric efficiency depends on the pump speed and the viscosity of the oil, which in turn depends on the working temperature of the oil. An empirical model of the gear pump volumetric efficiency suggested by Michael et al. [18] was adopted here. This model was obtained from experimental tests of 16 external flow gear pumps. The volumetric efficiency is correlated to the Stribeck non-dimensional number, also known as non-dimensional viscosity, which was first introduced in 1901 [19] to represent the bearing friction curves and is defined as the following:

$$
\bar{\mu}=\frac{\mu \cdot \omega}{\Delta P}=\frac{2 \pi}{60} \times \frac{\mu \cdot N}{\Delta P}
$$

where $\mu$ is the fluid viscosity (Pa.s), $\omega$ the shaft speed ( $\mathrm{rad} / \mathrm{s})$, and $\Delta P$ is the pressure difference $(\mathrm{Pa})$. The volumetric efficiency was calculated using the suggested correlation:

$$
\eta_{v}=1-\frac{6.8 \times 10^{-9}}{\bar{\mu}}-\frac{2 \times 10^{-5}}{\sqrt{\bar{\mu}}}
$$

The volumetric efficiency of the gear pump is shown in Figure 11 at a given pressure and pump speed and varying the working temperature from 20 to $150{ }^{\circ} \mathrm{C}$.

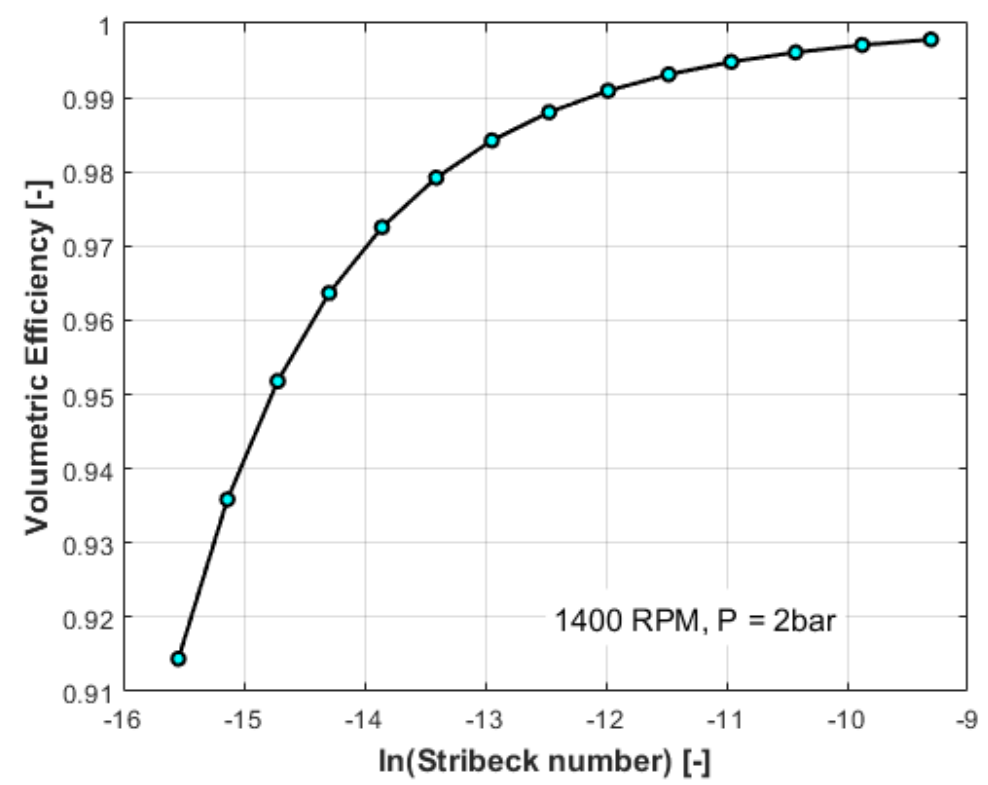

Figure 11. Volumetric efficiency of the oil gear pump for a given pump speed and pressure for different oil temperatures $\left(20-150^{\circ} \mathrm{C}\right)$.

Looking at Figure 11 and considering the operating temperature of the oil pump in the range of 120 to $150{ }^{\circ} \mathrm{C}$, its volumetric efficiency can be penalized significantly if the provided pressure is 2 bar. Therefore, an estimation of the pressure drop that the gear pump must overcome was calculated to obtain an estimation of the volumetric efficiency. Hence, the pressure drop was considered due to two main contributions: the pressure drop in pipes and fittings and in the evaporator. 
To calculate the pressure drop in the pipes and fittings of the diathermic oil circuit, the well-known Darcy-Weisbach friction factor was estimated using the implicit correlation for turbulent liquid flows in conduits suggested by Colebrook and White [20]:

$$
\frac{1}{\sqrt{f}}=-2 \ln \left(\frac{\varepsilon / D}{3.7}+\frac{2.51}{\operatorname{Re} \sqrt{f}}\right)
$$

The pressure drop in the pipes and fittings (fitting were considered using equivalent pipe length of each fitting) was calculated using Equation (13):

$$
\Delta P_{\text {pipe }}=\frac{1}{2} f \cdot \rho \cdot v^{2} \frac{L}{D}
$$

Instead, the pressure drop correlation deduced for mineral oil flow in a PHE presented by Bogaert and Bolcs [21] was used to calculate the Fanning friction factor of the hot fluid flow in the evaporator. This correlation is presented in Equation (14), and it was used as Equation (15) to calculate the pressure drop in the evaporator.

$$
\begin{aligned}
f & =\frac{11.215}{R e^{0.248}} \\
\Delta P_{e v} & =2 f \cdot \rho \cdot v^{2} \frac{L}{D}
\end{aligned}
$$

Therefore, the pressure drop of the hot fluid was calculated as the sum of Equations (13) and (15) to calculate the non-dimensional viscosity for all experimental data points. The resultant volumetric efficiency of the oil pump for the experimental database is shown in Figure 12 confirming the reliable performance of the oil pump in the temperature range of the tests.

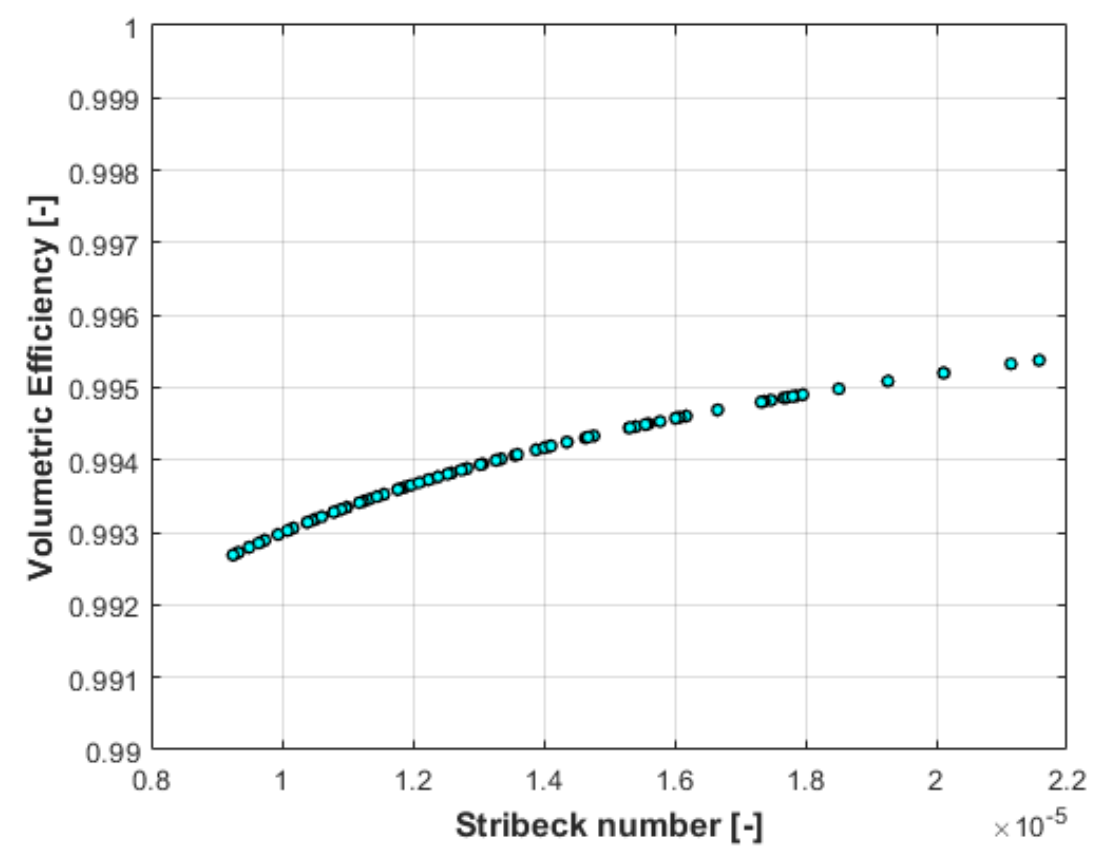

Figure 12. Volumetric efficiency of the oil pump for all experimental data points.

\subsection{Refrigerant Pump}

The volumetric efficiency, the isentropic efficiency, and the electromechanical efficiency of the refrigerant plunger pump were modeled using the experimental data. 


\subsubsection{Volumetric Efficiency}

The volumetric efficiency can be written as a function of the leakage flow rate as:

$$
\eta_{v o l}=\frac{\dot{m}_{a c t}}{\dot{m}_{t h}} \times 100=\frac{\dot{m}_{t h}-\dot{m}_{l k}}{\dot{m}_{t h}} \times 100=\left(1-\frac{\dot{m}_{l k}}{\dot{m}_{t h}}\right) \times 100
$$

where subscripts " $a c t$ " and " $k$ " refer to actual and leakage, respectively. The leakage mass flow rate of the pump was modeled using the adiabatic flow in a nozzle, in which the leakage flow travels from the pump discharge pressure to the suction pressure through small clearance gaps. The leakage mass flow rate using this nozzle throttle model can be deduced as the following neglecting the variation of the leakage flow liquid density with pressure:

$$
\dot{m}_{l k}=\rho_{l k} \cdot A_{l k} \cdot v_{l k}=\rho_{s u} \cdot A_{l k} \cdot v_{l k}
$$

where the subscript "su" refers to the suction. The fluid velocity in the throttle can be calculated using Bernoulli's equation:

$$
v_{l k}=\sqrt{\frac{2\left(P_{e x}-P_{s u}\right)}{\rho_{s u}}}=\sqrt{\frac{2 \Delta P}{\rho_{s u}}}
$$

Combining Equations (17) and (18), the leakage mass flow rate is derived as Equation (19):

$$
\dot{m}_{l k}=A_{l k} \sqrt{2 \rho_{s u} \cdot \Delta P}
$$

The throttle area $\left(A_{l k}\right)$ represents the average leak area of the pump that was modeled in this work using the non-dimensional viscosity as the following:

$$
\frac{A_{l k}}{A_{\text {bore }}}=a \cdot \bar{\mu}=a\left(\frac{\mu \cdot \omega}{\Delta P}\right)
$$

where $A_{\text {bore }}$ is the bore area of the piston chamber taken from the pump specification sheet, and $\omega$ is the shaft speed (rad/s). The empirical coefficient " $a$ " can be obtained using the minimization of the objective function $(f)$ presented in Equation (21) for each data point:

$$
f_{i}=\left(\frac{\eta_{v o l, i, c a l}-\eta_{v o l, i, \exp }}{\eta_{v o l, i, \exp }}\right)^{2}
$$

The coefficient " $a$ " was obtained for each data point and correlated to two nondimensional numbers of the pump, namely the suction Prandtl number $\left(P r_{s u}\right)$ and the reduced pump speed $\left(N_{r}\right)$ using the regression data fitting method.

$$
\begin{gathered}
a=f\left(P r_{s u}, N_{r}\right) \\
P r_{s u}=\frac{\mu_{s u} \cdot C_{p, s u}}{\lambda_{s u}} \\
N_{r}=\frac{N}{N_{\max }}
\end{gathered}
$$

where $N_{\max }$ is the maximum pump speed declared in the pump specification sheet (1500 rpm).

The calculated volumetric efficiency is shown versus the experimental volumetric efficiency in Figure 13, showing the good accuracy of the model. The volumetric efficiency model is needed to assess the real mass flow rate of the pump for different working conditions. The calculated mass flow rate of the pump using the pump speed as the input is plotted in Figure 13, confirming the accuracy of the model for the range of the working conditions of the pump obtained during the experiments. 

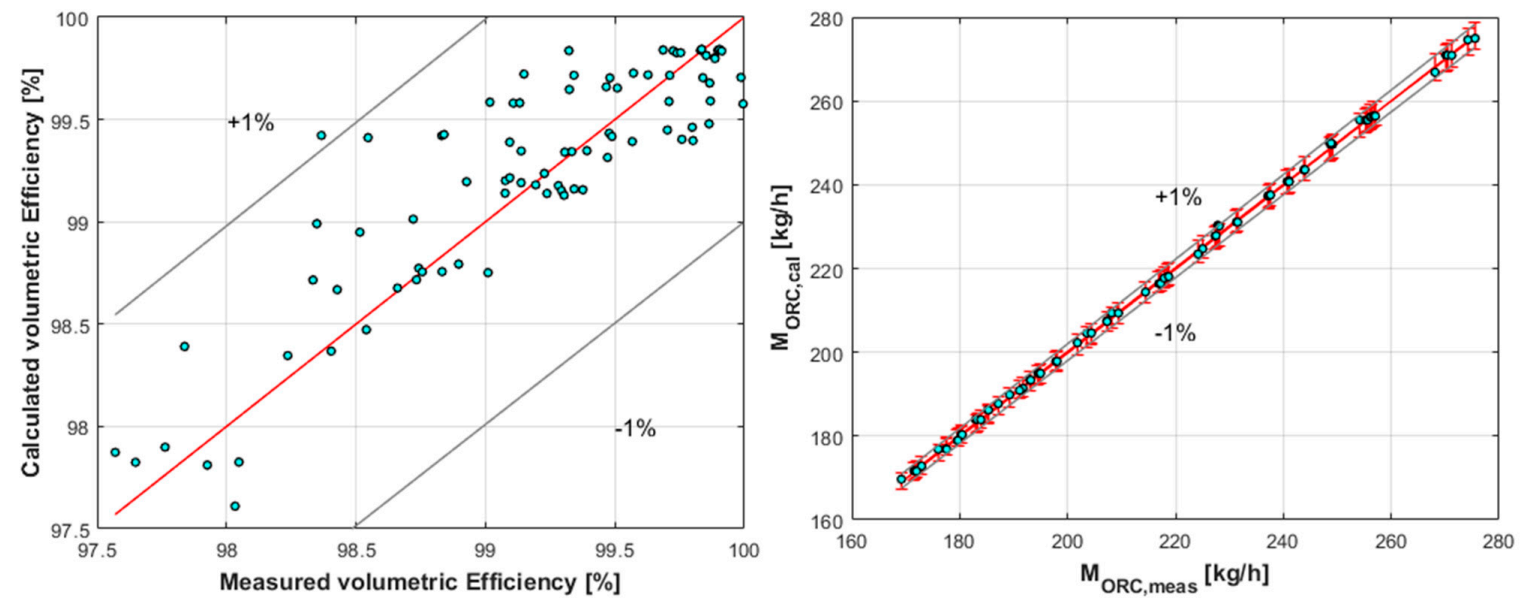

Figure 13. Measured and calculated pump volumetric efficiency (left) and pump mass flow rate (right).

\subsubsection{Isentropic Efficiency}

Like the volumetric efficiency, the isentropic efficiency is also modeled empirically. It is defined using Equation (25), in which the actual work of the pump is considered the sum of the reversible work and the shaft loss work, which in turn is correlated to the loss torque:

$$
\begin{gathered}
\eta_{i s}=\frac{\dot{W}_{\text {is }}}{\dot{W}_{\text {act }}} \times 100=\frac{\dot{W}_{\text {is }}}{\dot{W}_{\text {is }}+\dot{W}_{\text {loss }}} \times 100 \\
\dot{W}_{\text {loss }}=\frac{2 \pi}{60} \times N \cdot \tau_{\text {loss }}
\end{gathered}
$$

where $N$ is the pump speed (rpm) and $\tau_{\text {loss }}$ is the loss torque that is obtained empirically. The sensitivity analysis showed that the experimentally calculated isentropic efficiency can be correlated to the pump suction Prandtl number; thus, its non-dimensional form was adopted:

$$
\frac{\tau_{\text {loss }}}{\Delta P \cdot A_{\text {bore }} 1.5}=a \cdot P r_{s u}
$$

where " $a$ " is the empirical coefficient that is correlated to the suction Prandtl number $\left(P r_{s u}\right)$ and the reduced pump speed $\left(N_{r}\right)$ using the minimization of the difference between the simulated isentropic efficiency and the experimentally measured values like Equation (21). The calculated isentropic efficiency using the model is depicted in Figure 14, showing good accuracy for most data points. Moreover, the predicted pump outlet temperature is plotted, showing excellent accuracy.
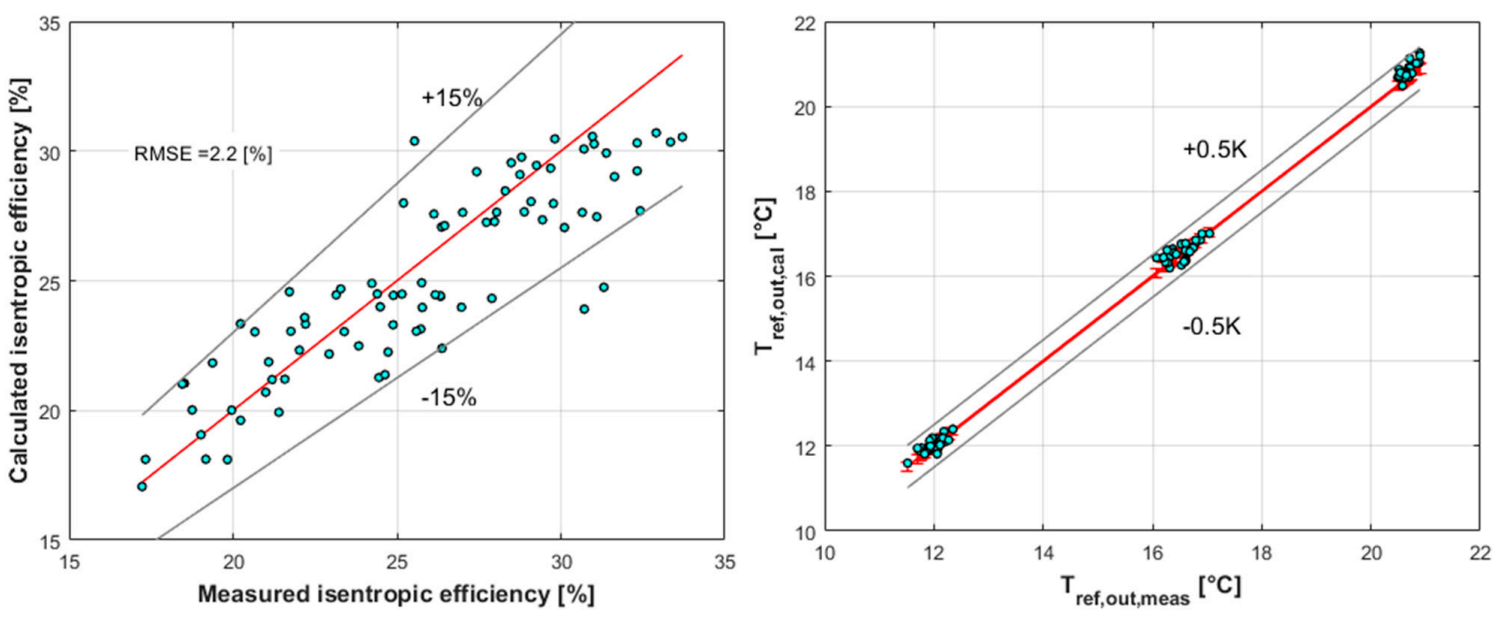

Figure 14. Measured and calculated pump isentropic efficiency (left) and discharge temperatures (right). 


\subsubsection{Electromechanical Efficiency}

The electric power consumption of the pump is higher than its thermodynamic power due to mechanical losses in the shaft coupling and bearings and the electric losses in the electric motor. Considering the sum of the mechanical and electrical losses, the electromechanical efficiency is defined as the following:

$$
\eta_{e l-m e c h}=\frac{\dot{m}\left(h_{e x}-h_{s u}\right)}{\dot{W}_{e l, m e a s}} \times 100
$$

where the denominator is the measured pump electric power consumption (active power). In the model, the electric power consumption is correlated to the pump reversible work using Equation (29):

$$
\begin{gathered}
\dot{W}_{e l, c a l}=a \cdot \dot{W}_{r e v}^{b} \\
\dot{W}_{r e v}=\dot{m} \frac{\Delta P}{\rho_{s u}}=\dot{m} \frac{P_{e x}-P_{s u}}{\rho_{s u}}
\end{gathered}
$$

where " $a$ " and " $b$ " are the empirical coefficients found by minimization of the objective function for electromechanical efficiency as in Equation (21). Therefore, the pump electric power consumption was calculated using Equation (31):

$$
\dot{W}_{e l}=30.6 \dot{W}_{\text {rev }} 0.53
$$

The pump electric power consumption and its electromechanical efficiency calculated using the presented empirical models are presented in Figure 15, showing good agreement between the suggested model and the experimental data.
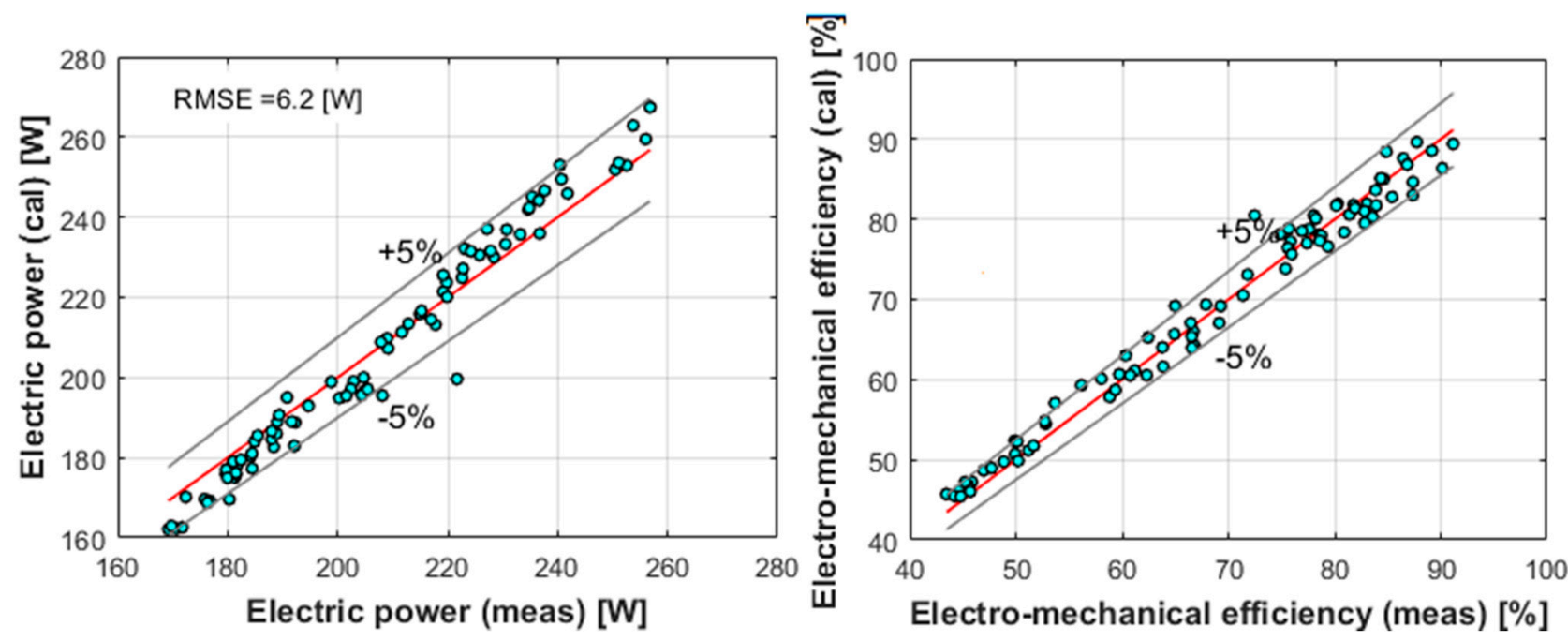

Figure 15. Measured and calculated pump electric power (left)and electromechanical efficiency (right).

\subsection{Evaporator and Condenser}

Several geometry-independent models for single-phase, boiling, and condensing flows were used to determine the most accurate combination for the thermal modeling of the evaporator and the condenser of the ORC unit. Hence, hydraulic modeling of the PHEs was firstly elaborated, and then the developed hydraulic models were used in the thermal modeling. 


\subsubsection{Hydraulic Modeling}

The pressure drop in the evaporator and the condenser of the ORC unit was modeled in the refrigerant stream using the retuned empirical correlations, while it was neglected in the hot fluid stream in the evaporator and the cold fluid stream in the condenser. Hydraulic modeling of the PHEs was preliminarily performed to better assess their thermal performances afterward. Indeed, pressure drop mainly influences the calculated degree of subcooling in the condenser and of the superheating in the evaporator.

In addition, solving a PHE using moving boundary or finite volume methods requires the resolution of the pressure distribution inside the PHE. Indeed, a specific calculation of the total pressure drop can result from infinite combinations of the pressure distribution in the channel, which in turn affects the thermal modeling. If a pressure drop correlation that depends on the local thermal resolution is adopted, the thermal and hydraulic correlations become coupled, and an iterative solver is needed for each zone/cell of the PHE consequently. However, since the mechanistic hydraulic modeling of the PHEs is out of the scope of the present work, an estimation of the pressure drop distribution was obtained using the relevant empirical models to obtain the hydraulic resolution independently from the thermal solver and make them decoupled.

The pressure drop model is inspired by [22], suggested for single-phase flows in PHEs and used for boiling pressure drop modeling in PHEs by Desideri et al. [23] as in Equation (32).

$$
\Delta P_{i}=a \frac{G^{2}}{2 \rho_{i}}
$$

where $G$ is the mass flux $\left(\mathrm{kg} / \mathrm{m}^{2} \cdot \mathrm{s}\right), \rho_{i}$ is the average zone/cell density $\left(\mathrm{kg} / \mathrm{m}^{3}\right)$, and $a$ is the empirical coefficient to be found by minimization of the objective function $(f)$ defined as the sum of the square of the relative deviation between the calculated pressure drop and the measured values as presented in Equation (33):

$$
f=\sum_{i=1}^{n}\left(\frac{\Delta P_{\text {cal }, i}-\Delta P_{\text {meas }, i}}{\Delta P_{\text {meas }, i}}\right)^{2}
$$

The results of the model and the pressure distribution in the condenser for one data point are presented in Figure 16. The root mean square error (RMSE) of the results is low, showing good agreement between the model results and the experimental data. The pressure distribution shows that the significant share of the total pressure drop is accounted for in the gas zone despite its marginal enthalpy change. In the gas zone, the fluid velocity is higher than the liquid and the two-phase zones; thus, pressure drop increases.
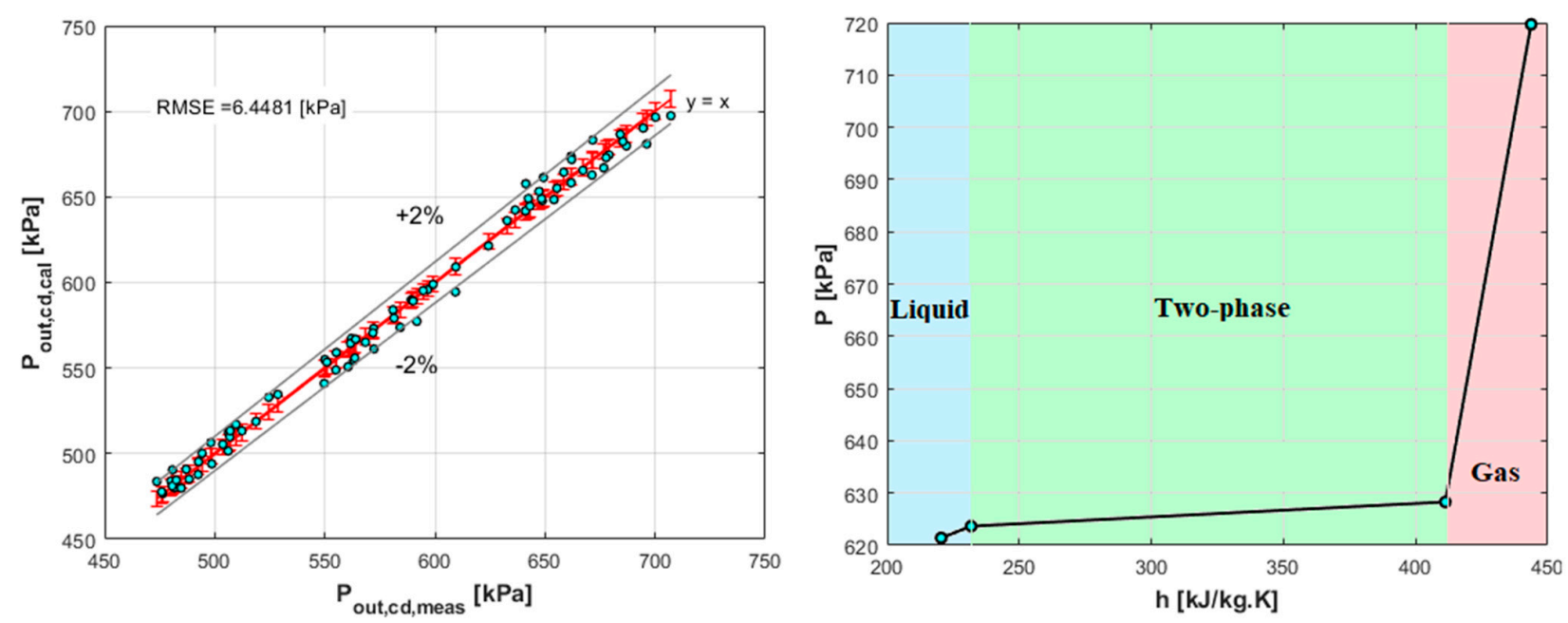

Figure 16. Calculated and measured pressure drop of the condenser (left) and pressure drop resolution in different heat transfer zones in the condenser (right). 
The results for the evaporator are presented in Figure 17, showing even higher accuracy (lower RMSE) compared to the evaporator results. The lower accuracy of the results of the evaporator is due to the higher deviation of the evaporator experimental data around the mean value. The inlet pressure of the evaporator is directly affected by the pulses of the plunger pump and the variations of the heat source temperature as well. On the contrary, the plunger pump pulses were almost damped at the condenser inlet, and the water inlet temperature was much more stable due to the high mass flow rate of the cooling circuit.
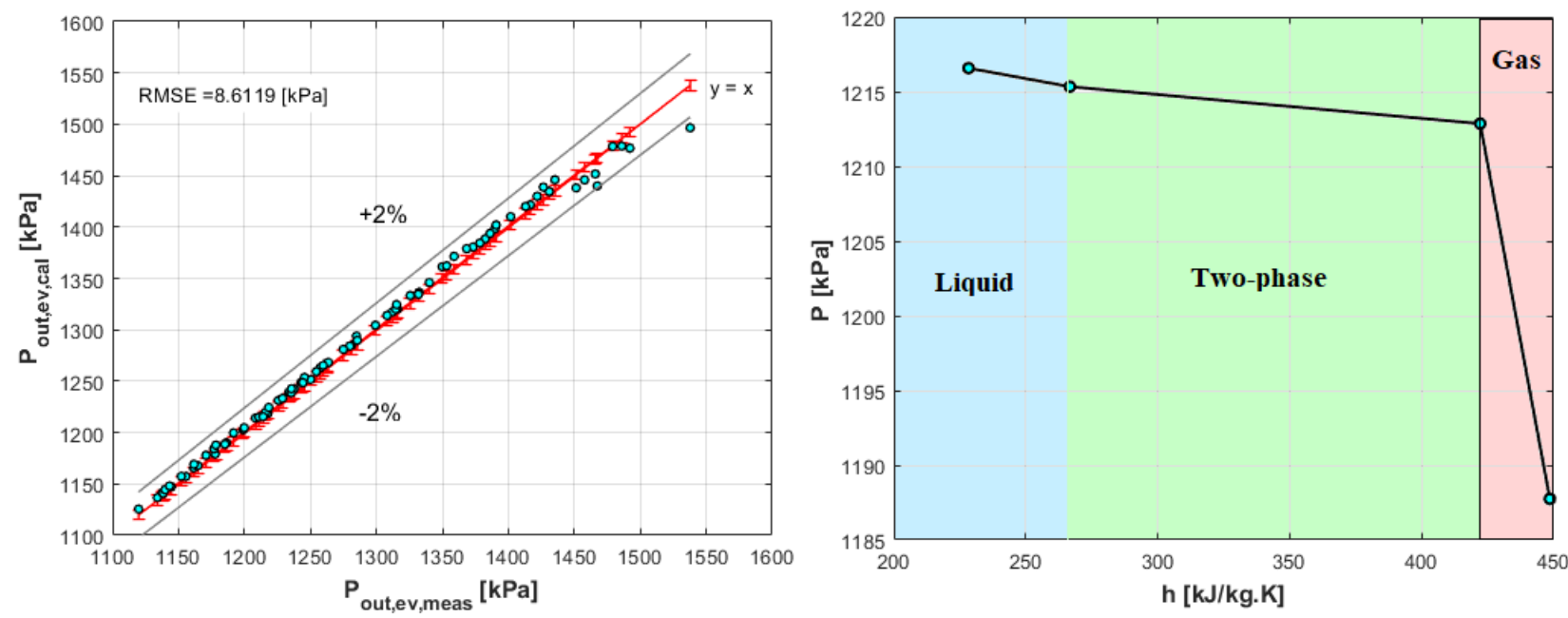

Figure 17. The calculated and measured pressure drop of the evaporator (left) and pressure resolution in different heat transfer zones in the evaporator (right).

Finally, it should be noted that this approach should be taken with caution for general models of the heat exchangers especially if the pressure resolution is particularly important. However, for this work, a compromise between the accuracy and the computational speed was considered. The obtained empirical coefficients for the evaporator and condenser are reported in Table A1.

\subsubsection{Thermal Modeling}

The moving boundary method was used in this work for spatial modeling of the PHEs. In the case of a general flow in a HE, both streams may change the phase, and consequently five zones can exist as shown in Figure 18.
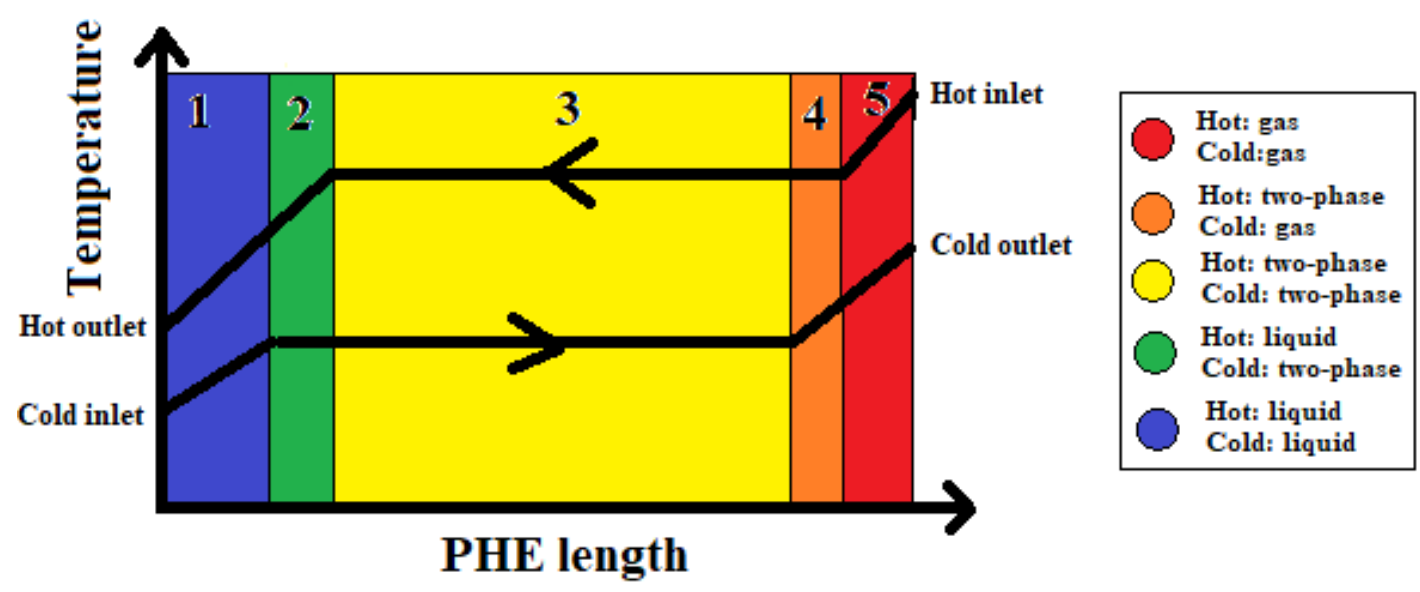

Figure 18. The possible distribution of heat transfer zones in a heat exchanger when both streams change the phase. 
Regarding the PHEs in this work, only the refrigerant stream changes the phase, and the hot stream in the evaporator and the cold stream in the condenser are in the single-phase liquid, so three zones are presented. Hence, the area of the plate is divided into three zones, which were determined using the liquid and gas saturation enthalpies of the refrigerant. The calculated thermal load of the refrigerant stream is assumed to be fully transferred to the other stream in both the evaporator and the condenser, thus establishing zone boundaries.

The next step was calculating the convective heat transfer coefficients (CHTCs) in the hot and cold streams using the relevant correlations for each heat transfer zone to obtain the overall CHTC of the zone. The pressure drop in each zone was preliminarily calculated before running the thermal solver using the method and the correlation elaborated in the previous subsection.

Several geometry-independent, single-phase, boiling, and condensation CHTC correlations were tested to find the best combination that could predict the experimental data of the evaporator and the condenser of the ORC unit. The four single-phase correlations are the Ditteus-Boettler correlation [24], its modified correlation suggested by Sieder and Tate [25] considering the variations of the viscosity of the fluid due to the difference between the wall temperature and the bulk temperature, the Bogaert-Bolcs [21] correlation, and the correlation suggested by Kays and Crawford [26]. Except for the Bogaert-Bolcs model, which was suggested for mineral oil in a PHE and is the accepted correlation among Swedish manufacturers [27], all correlations were obtained for turbulent flows in tubes. These correlations are reported in Appendix C.

To fit the models with the experimental data of the evaporator and the condenser, some effective coefficients were tuned by minimization of the objective function using the genetic algorithm optimization method. The objective function is the calculated area of the PHE needed to obtain the same thermal performance as the experimental data. More precisely, the sum of the calculated areas of the three zones must be equal to the total heat transfer area of the plate. Therefore, the objective function is defined as the following:

$$
f=\sum_{i=1}^{n}\left(\frac{A_{c a l, i}-A}{A}\right)^{2}
$$

where $n$ is the number of experimental points (84 points), $A$ is the heat transfer area of the plate taken from the manufacturer datasheet, and $A_{c a l, i}$ is the calculated area of the plate:

$$
A_{\text {cal }}=A_{L}+A_{t p}+A_{V}
$$

The results of the optimization are presented in the following for the evaporator and the condenser of the ORC unit using R134a as the working fluid, diathermic oil (H22) as the hot fluid, and water as the cooling medium.

- Condenser:

The four considered single-phase CHTC correlations in this work were combined with the two condensation CHTC correlations: the Claesson [28] and Kuo [29] models. The best results are obtained using Kays and Crawford single-phase and Claesson condensation correlations. One coefficient was found for water stream correlation, two for liquid and gas single-phase R134a, and one for the condensation correlation (four in total). The obtained coefficients for the CHTC models are reported in Table A2.

The results of the selected model are shown in Figure 19, neglecting a few points (seven points have been excluded for the condenser modeling results since the very low temperature pinch required a different set of empirical coefficients for the CHTC model compared to that able to predict the remaining data with good accuracy). The predicted performance of the condenser shows the good agreement of the model with the experimental data. The outlet temperature of the refrigerant is close to the inlet temperature of the water due to the relatively high mass flow rate of water and the large size of the 
condenser. Moreover, the high CHTC calculated in the two-phase zone can be recognized, with a noticeable relatively large temperature change in the water stream.
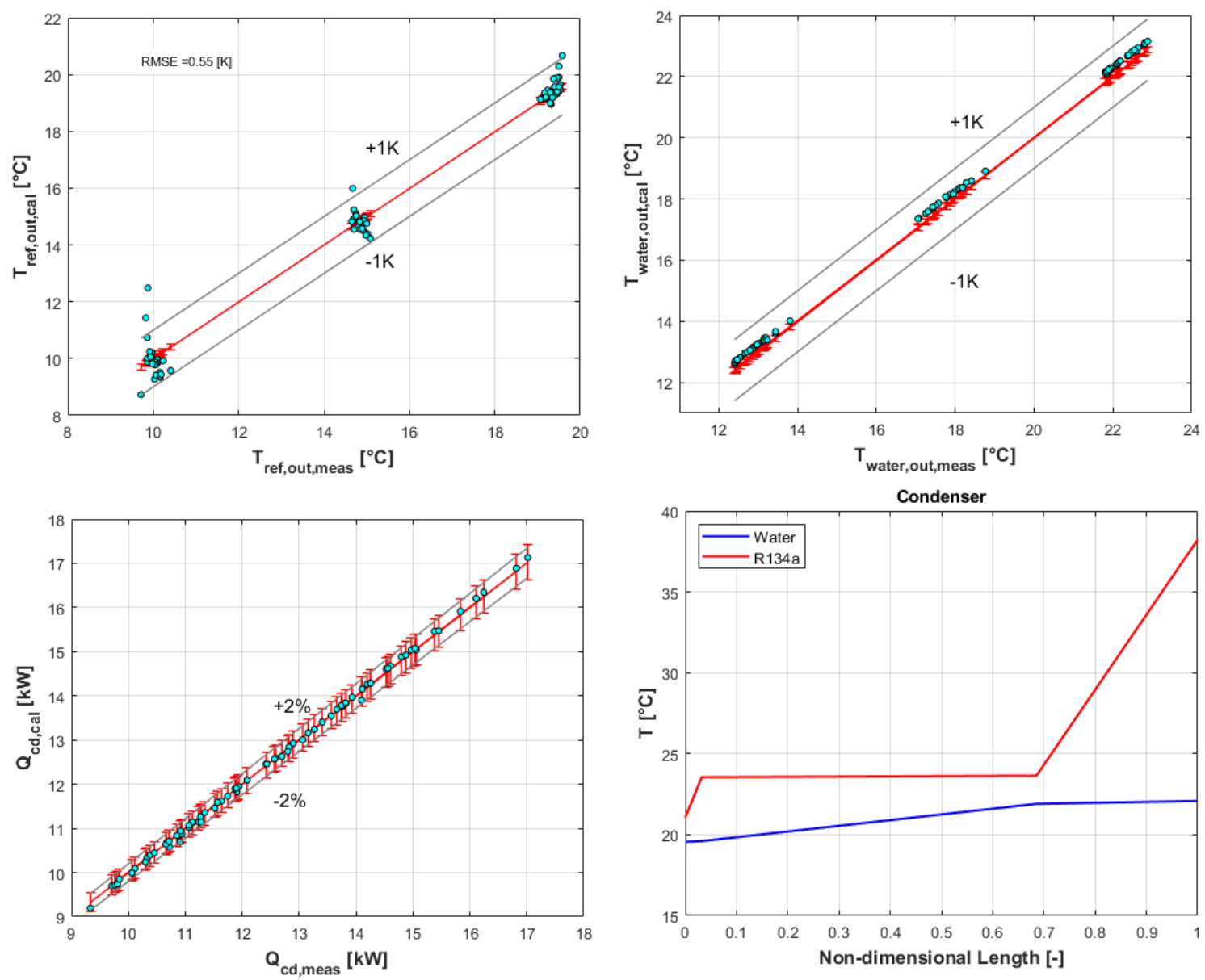

Figure 19. Results of the condenser hydrothermal model vs. experimental data: refrigerant discharge temperature (top-left), water discharge temperature (top-right), thermal load in the refrigerant side (bottom-left), and temperature profile for one of the experimental points (bottom-right).

- Evaporator:

Similar to the condenser modeling, four single-phase and three boiling CHTC models were considered. The single-phase correlations were the same as for the condenser, and the boiling correlations were Hsieh et al. [30], Desideri et al. [23], and Yan et al. [31]. Hsieh's correlation was suggested for R410 boiling in PHEs, Desideri's correlation for R245fa and R1233ZD in PHEs, and Yan's for R134a in PHEs. Due to the presence of more variables affecting the performance of the evaporator and the wider range of the working conditions, the coefficient of the boiling CHTC correlation was found for each single data point, then it was correlated to the Re and Pr numbers of the diathermic oil and R134a streams using the regression data fitting method.

The best combination of the models was found using the Kays and Crawford model for liquid and gas single-phase CHTC of R134a using coefficients of the original model, the Bogaert-Bolcs model for single-phase oil flow using coefficients of the original model, and Yan's model for boiling CHTC with one coefficient correlated to the flow characteristics of the oil and the refrigerant streams. The original coefficients of the aforesaid singlephase correlations and the correlated coefficient of Yan's model are reported in Table A3. The results of the obtained model are shown in Figure 20. The predicted performance of the evaporator shows very good agreement between the model and the experimental data. 

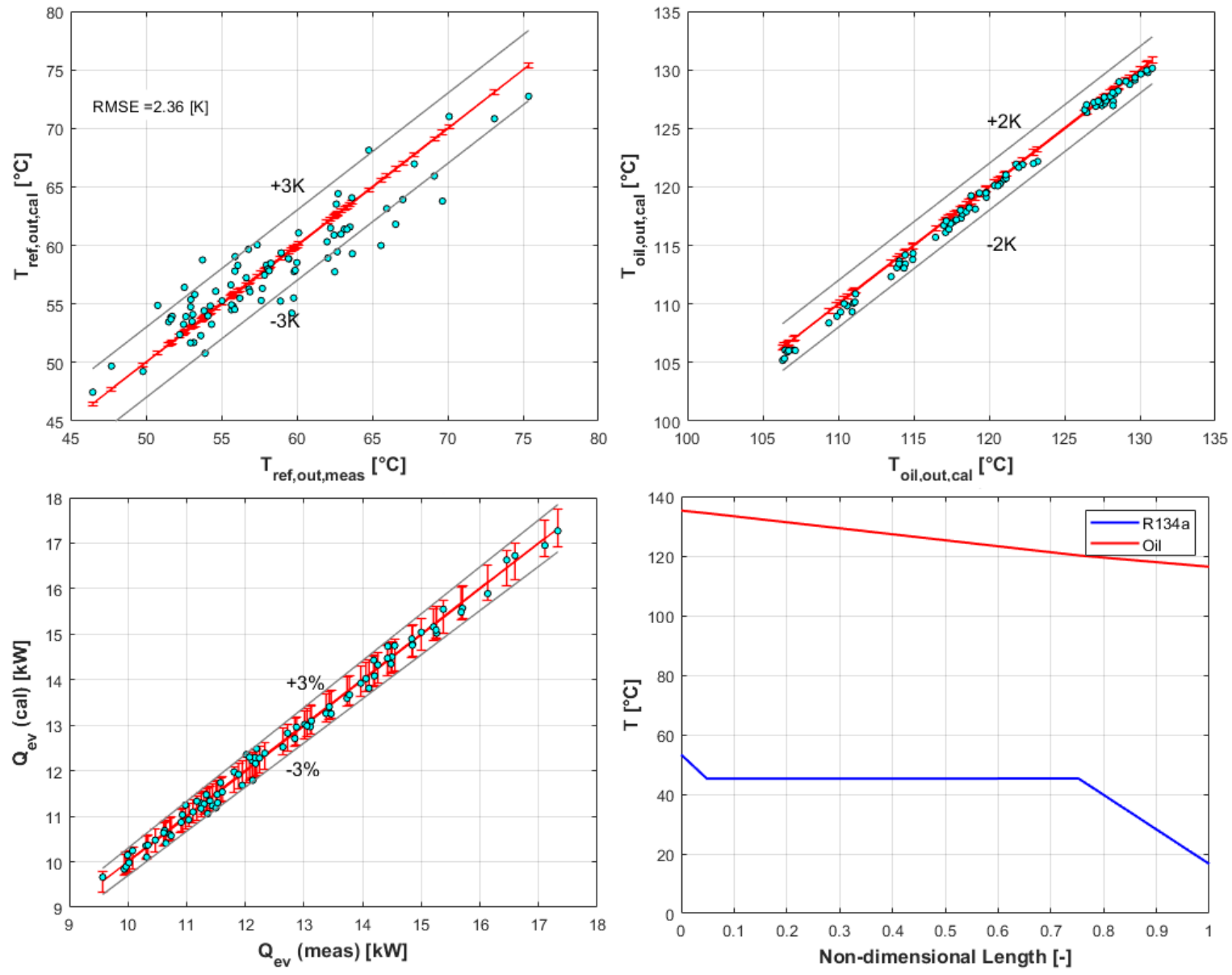

Figure 20. Results of the evaporator hydrothermal model vs. experimental data: refrigerant discharge temperature (top-left), diathermic oil discharge temperature (top-right), thermal load in the refrigerant side (bottom-left), and temperature profile for one of the experimental points (bottom-right).

The lower accuracy of the evaporator model compared to the condenser one is due to the higher ambient heat losses from the evaporator compared to the condenser because of the significantly higher temperature of the evaporator. The heat losses also occur in the hot fluid pipe since the temperature sensors had a distance from the evaporator inlet and outlet ports. Another reason for the lower accuracy goes back to the higher fluctuations of the evaporator inlet and outlet pressures due to the direct impact of the plunger pump pulses and variations of the heat source temperature as discussed in the hydraulic modeling subsection. Nonetheless, the accuracy of the model for both the evaporator and condenser of the ORC unit can be considered satisfactory for rating their performances properly.

\subsection{Scroll Expander}

The scroll expander is an open-drive, lubricated machine converted from a refrigerant compressor. The test bench is not equipped with a dedicated oil separator circuit; hence, the lubricant oil is mixed with the refrigerant and circulates in the system. It is modeled using a semi-empirical model developed by some authors of this work, which simulates the expansion process as a polytropic one. Moreover, a more detailed suction pressure drop model is included compared to what is commonly used in literature. The mechanical losses are modeled using a lumped loss torque, which is correlated to the expander shaft speed. The inputs to the model are the expander suction pressure and temperature; expander shaft speed; expander discharge pressure; expander geometrical parameters, BVR and $\mathrm{SV}$, known from the manufacturer datasheet; and the empirical coefficients. The model outputs are the expander shaft power, the isentropic efficiency, the volumetric efficiency 
$(F F)$, and the expander mass flow rate. The expander performances were mapped using the model and are presented in Figure 21. Further details on the expander paper can be found in [17].
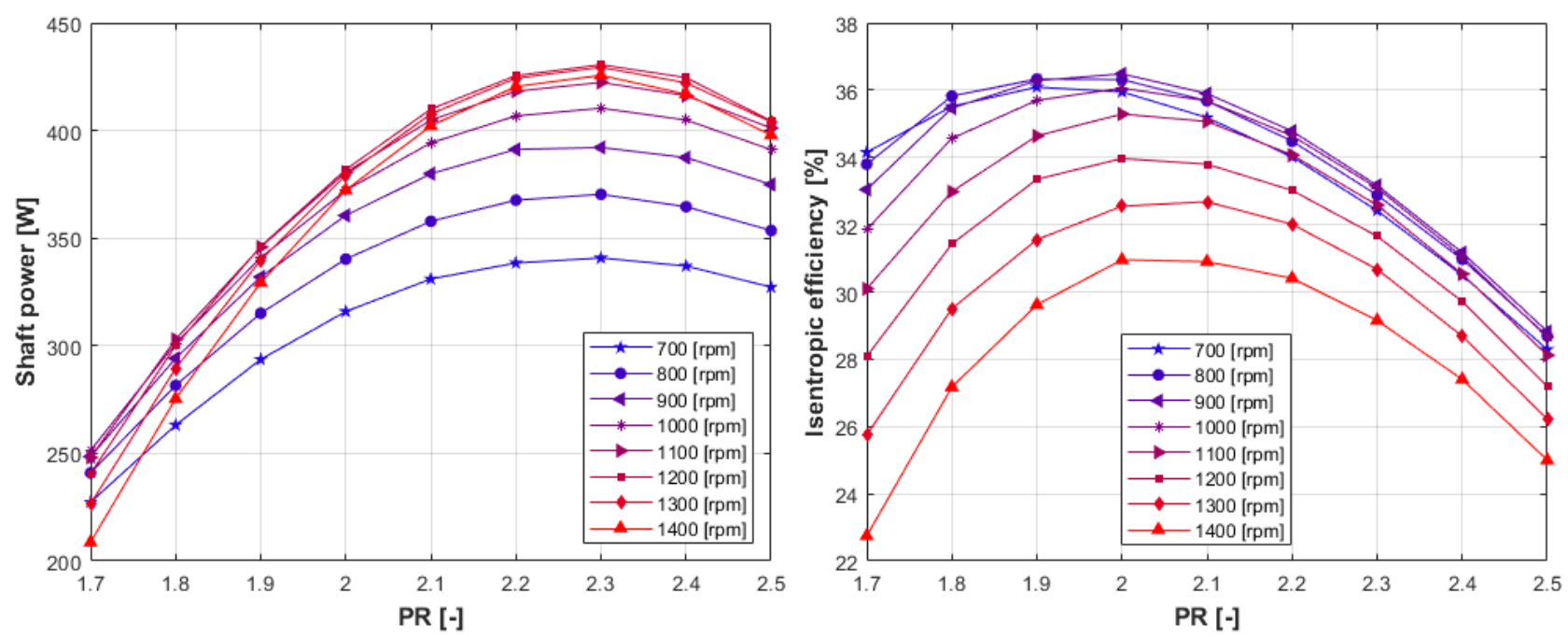

Figure 21. Expander shaft power (left) and isentropic efficiency (right) with expander pressure ratio (PR) and shaft speed $\left(\mathrm{T}_{\text {su,exp }}=65^{\circ} \mathrm{C}, \mathrm{P}_{\text {su, exp }}=15\right.$ bar, $\left.\mathrm{T}_{\mathrm{amb}}=15^{\circ} \mathrm{C}\right)$.

\section{System Performance Mapping}

The ORC system was simulated using a component-oriented modeling approach that refers to as functions the models of the different components discussed above. The system solver takes the system boundaries as inputs plus a set of assumptions that are relevant for the ORC system operation. The system boundaries are: (i) the hot fluid inlet temperature to the evaporator; (ii) the cold fluid inlet temperature to the condenser; (iii) the hot fluid pump speed; (iv) the cold fluid flow rate; (v) the expander shaft speed; and (vi) the ambient temperature. The assumptions are that: (i) the superheating degree in the evaporator is equal to $5 \mathrm{~K}$, and (ii) the subcooling degree in the condenser is $5 \mathrm{~K}$. The solver inputs and outputs are shown in Figure 22.

\section{Inputs:}

Heat source supply
conditions $(\mathrm{T}, \mathrm{N})$

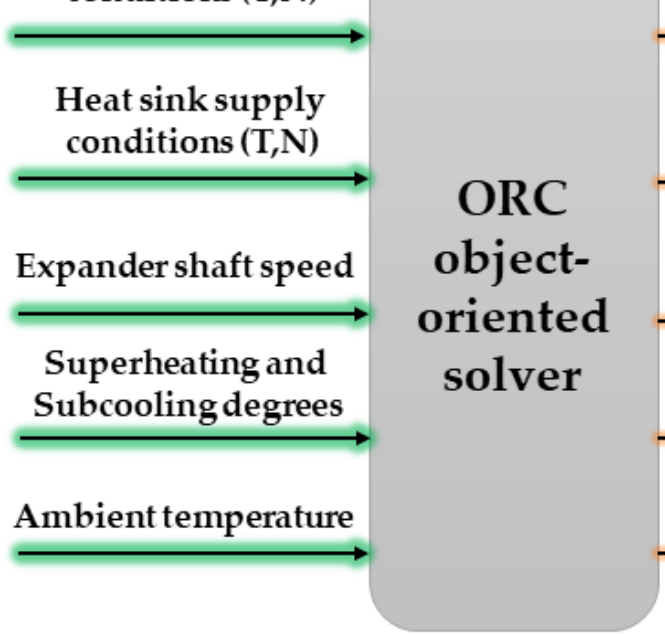

\section{Outputs:}

\section{Refrigerant, $\mathrm{HF}, \mathrm{CF}$} mass flow rate

All energy transfers (work and thermal)

\section{Systeminternal} thermodynamic states $(\mathrm{T}, \mathrm{P}, \mathrm{h}, \mathrm{S})$

\section{Refrigerant pump} speed

Efficiency of the system and its components

Figure 22. Inputs and outputs of the ORC object-oriented model. 
The solver initiated using some guess values found in three iterative loops as shown in Figure 23. In the inner loop, the refrigerant pump speed was found to reach the preset superheating degree in the evaporator. In the next loop, the pump discharge pressure, which is directly associated with the expander suction pressure, was adjusted so that for the given pressure ratio the mass flow rate of the scroll expander was close to the mass flow rate produced by the refrigerant pump. Then, the condenser function was solved, and its discharge temperature was used to update the guess value of the pump suction temperature. In the outer loop, the expander discharge pressure, which determines the condenser pressure, was found to reach the preset subcooling degree in the condenser. The loops were terminated when the residuals of the objective parameters were small enough.

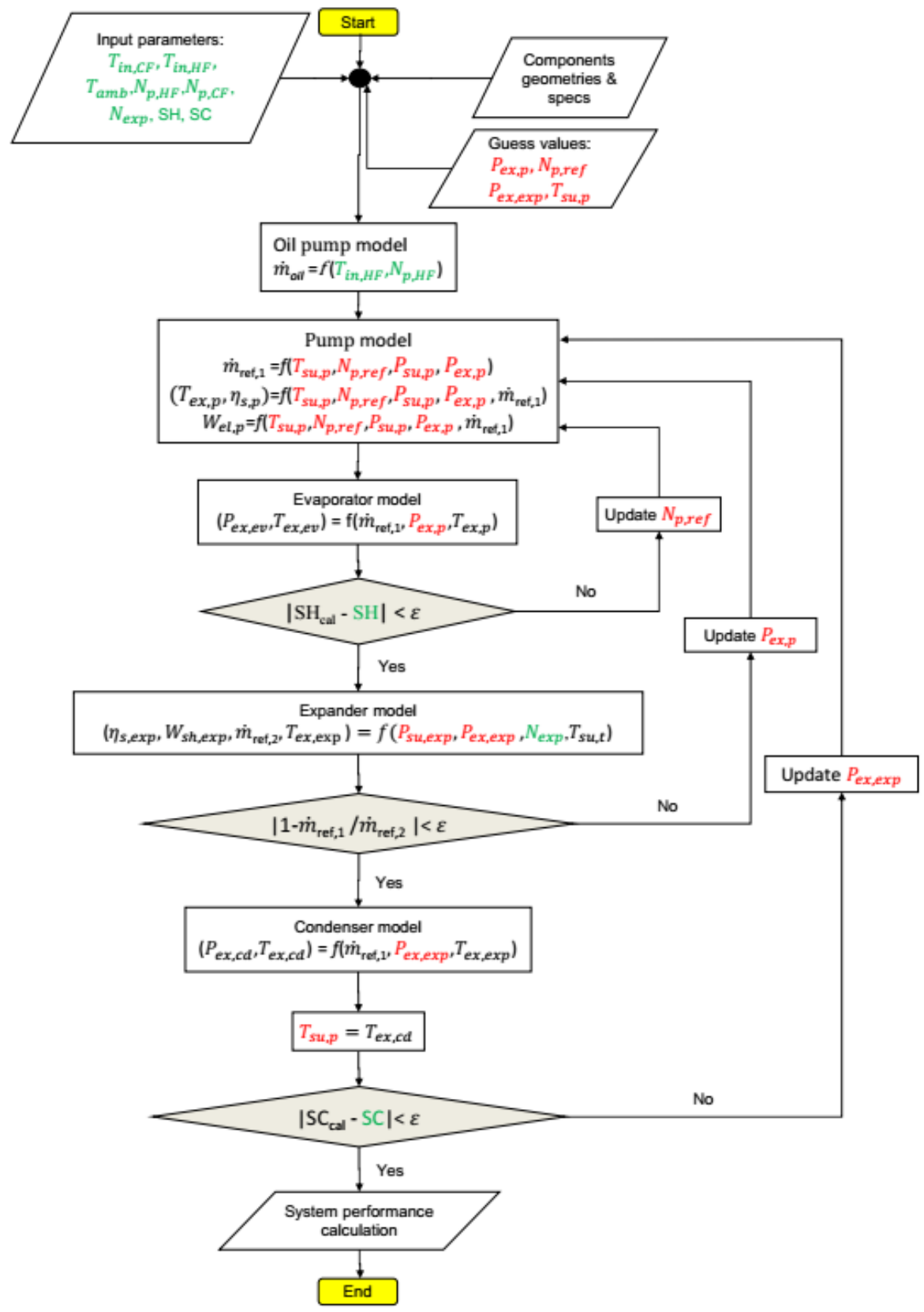

Figure 23. Flow chart of the object-oriented solver of the ORC system.

The system performances were mapped in terms of net electric power and efficiency for different heat source temperatures and expander shaft speeds as presented in Figure 24. The range of the variable parameters was kept as in the experimental data to avoid ex- 
trapolation of the semi-empirical models. The system performances improve at higher heat source temperatures, which is associated with the available thermal load in the heat source. Moreover, the peaks of the net electric performances were obtained for shaft speeds significantly lower than the electric generator maximum shaft speed (1500 rpm). This is due to the conditions of the experimental data of the scroll expander, which were used to tune the semi-empirical model as discussed in the following.
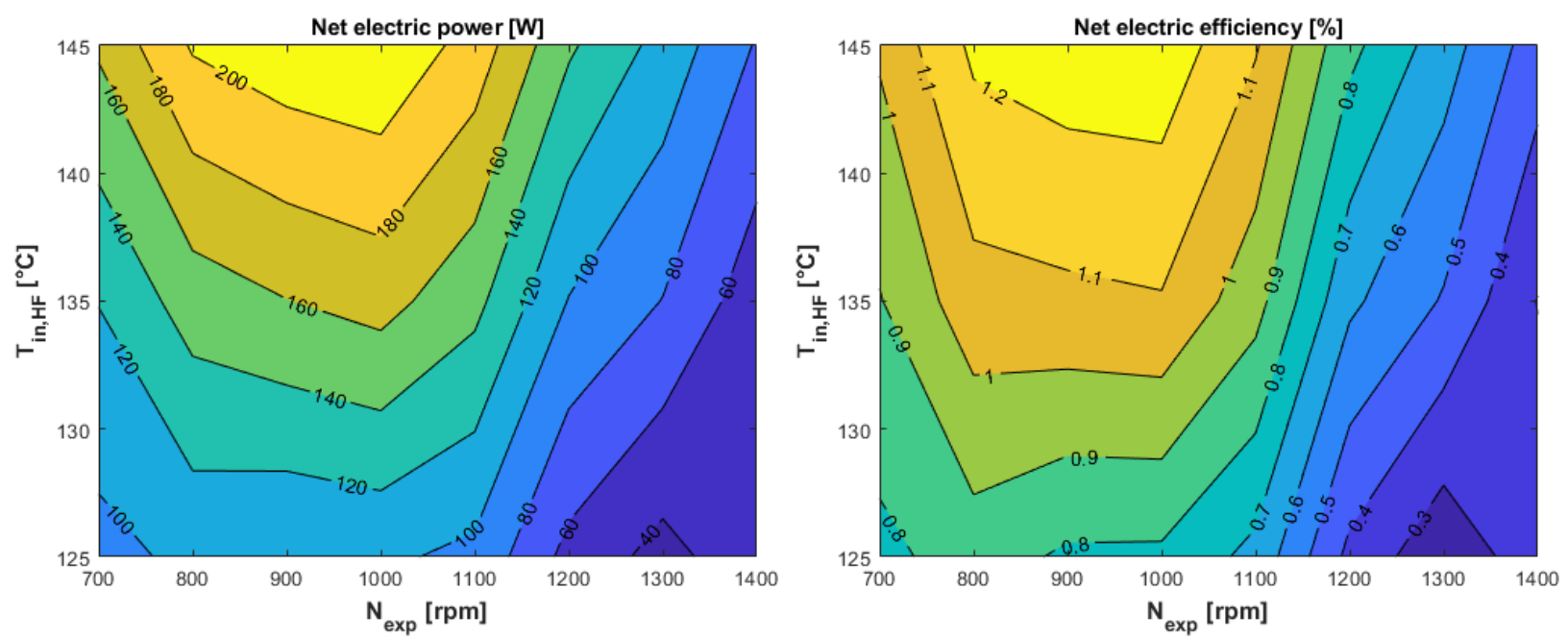

Figure 24. Net electric work (left) and net electric efficiency (right) maps of the ORC system with the heat source temperature and the expander shaft speed $\left(\mathrm{N}_{\mathrm{p}, \mathrm{HF}}=1400 \mathrm{rpm}, \mathrm{SH}=5 \mathrm{~K}, \mathrm{SC}=5 \mathrm{~K}, \mathrm{~T}_{\mathrm{in}, \mathrm{CF}}=15^{\circ} \mathrm{C}, \mathrm{T}_{\mathrm{amb}}=15^{\circ} \mathrm{C}\right)$.

During the test campaign, high shaft speeds were achieved when the shaft torque was reduced resulting in a drop in the shaft power. In other words, if the electric generator produced enough power, the expander shaft power remained lower than the generator's nominal speed due to the generator brake torque as shown in Figure 25. Therefore, the expander model reflects this phenomenon in higher shaft speeds, leading to a lower net electric power and net electric efficiency.

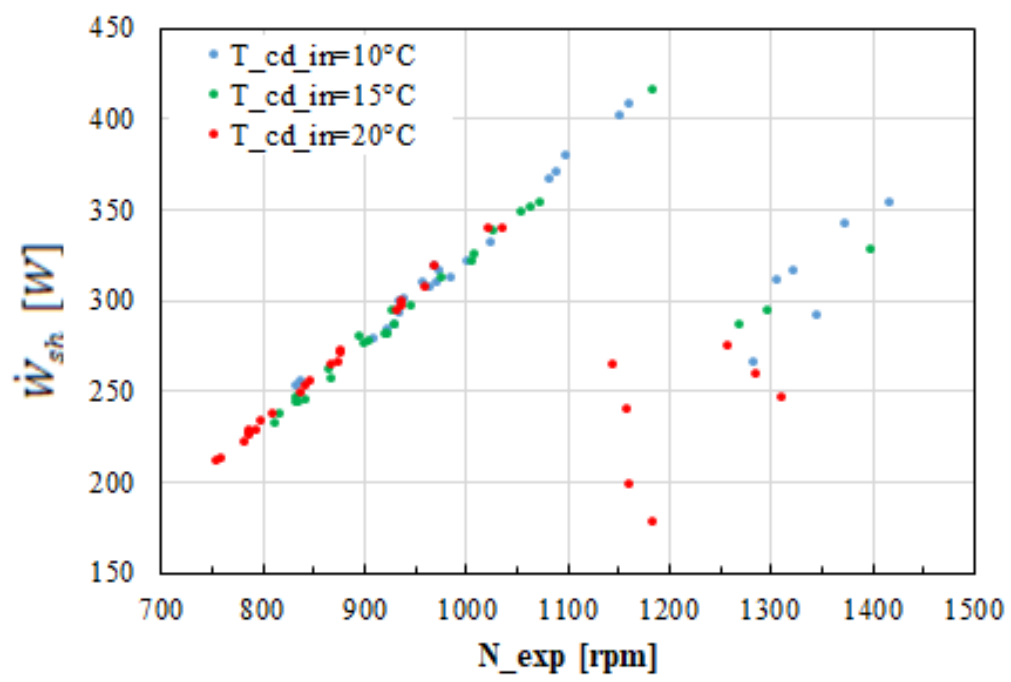

Figure 25. The expander shaft work with the expander shaft speed colored according to the cold fluid inlet temperature in the condenser.

\section{Conclusions}

This paper aims at presenting the results of the experimental tests of a micro-scale ORC unit in its off-design conditions. The results reveal the limitations of the test bench in 
reaching higher net electric power and efficiency. Furthermore, the non-negligible impact of the plunger pump on the performance and reliability of the ORC unit is presented. The experimental results were used to model the different system components using empirical models to predict the electrical performance of the ORC unit at varying working conditions. Based on the analysis carried out, the following conclusions can be drawn:

- The system performances are low due to some limitations of the components, especially the available thermal power in the heat source and the electric generator maximum speed;

- The impact of the pump performance is non-negligible, especially for micro-scale units. The losses in the pump isentropic efficiency and the electric losses in the variable speed motor can result in negative net electric power of the system in some working conditions;

- The pump isentropic efficiency increases with the refrigerant mass flow rate, which is associated with the pump speed. This shows that the pump is overdesigned for the range of the flow rates of the tests;

- The expander filling factor reduces almost linearly with the shaft speed. Moreover, it reduces with the expander pressure ratio;

- The expander shaft power increases with the refrigerant flow rate. The expander isentropic efficiency reduces with the expander shaft speed.

Despite the system being designed to test different expander devices such as the SANDEN TRS090F scroll compressor converted into an expander in various working conditions, the analysis highlights that the appropriate selection of the pump is crucial to achieving ORC system efficiencies in the range of $5 \%$ to $10 \%$ in the case of low-grade WHR applications.

Author Contributions: Conceptualization, R.M.; methodology, E.H. and L.C.; software, R.M.; validation, R.M.; formal analysis, R.M.; investigation, R.M.; resources, L.C.; data curation, E.H.; writingoriginal draft preparation, R.M., and L.C.; writing-review and editing, E.H. and E.B.; supervision, E.H., E.B. and L.C.; project administration: L.C. All authors have read and agreed to the published version of the manuscript.

Funding: This research received no external funding.

Institutional Review Board Statement: Not applicable.

Informed Consent Statement: Not applicable.

Data Availability Statement: Not applicable.

Acknowledgments: The authors wish to thank Comit International Srl for its support in the design and set up of the new test rig. Furthermore, the authors wish to thank also S.TRA.TE.G.I.E. Srl (www.strategiesrl.com, accessed on 20 December 2020) for the development of the initial test bench.

Conflicts of Interest: The authors declare no conflict of interest.

\section{Nomenclature}

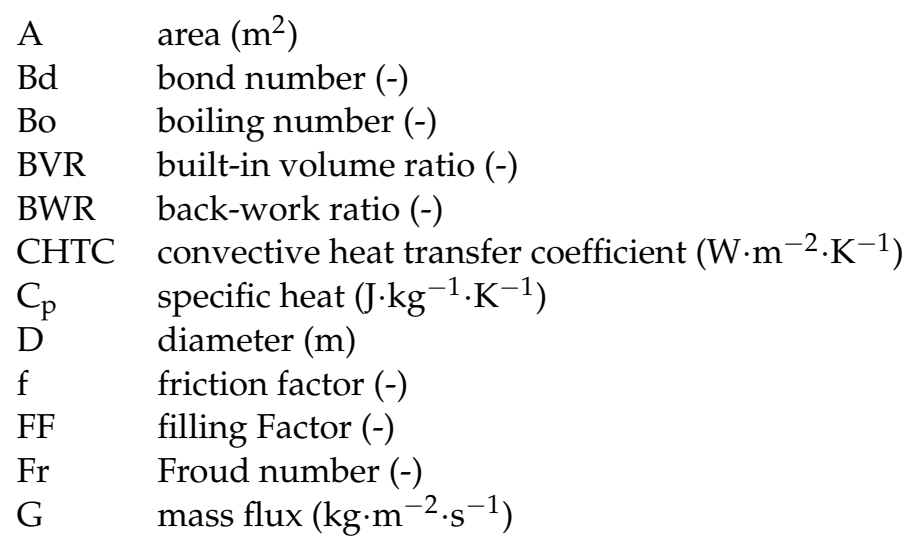




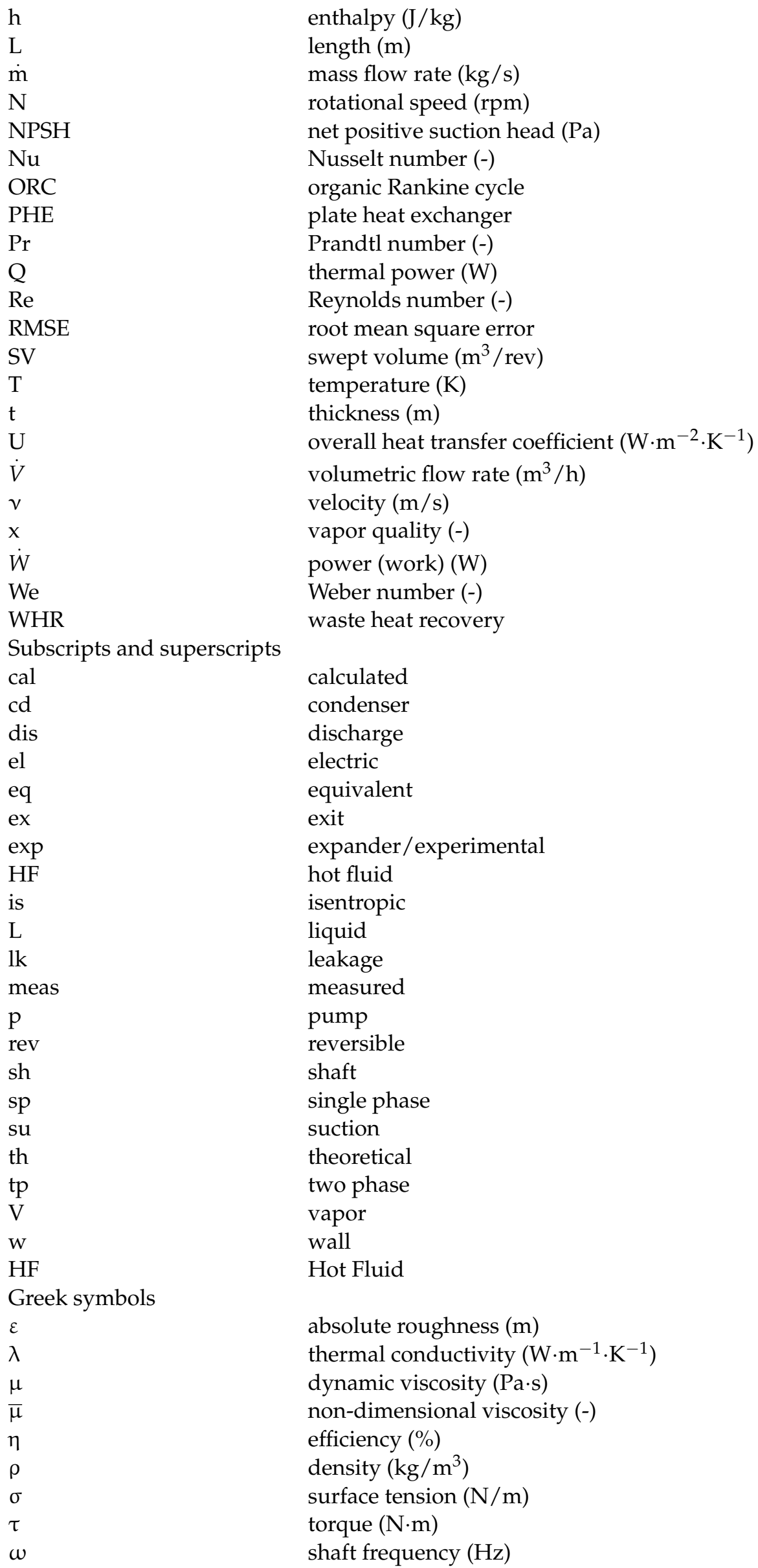




\section{Appendix A. Properties of the Diathermic Oil (Texatherm HT22)}

Properties of the diathermic oil were calculated using the table of properties provided by the manufacturer. Then, the following correlations were found to fit the tabular data.

$$
\begin{gathered}
C_{p}=3.658 T+827.4 \\
h=\int_{0}^{T} C_{p} d T=\frac{3.658}{2} T^{2}+827.4 T \\
\mu=1.022 \times 10^{41} T^{-16.99} \\
\lambda=-7.253 \times 10^{-5} T+0.1551
\end{gathered}
$$

\section{Appendix B. Uncertainty Analysis}

Two types of standard uncertainty are presented by Jianfeng Yu et al. [32]: the standard uncertainty of measurement tools (type A) and the standard uncertainty of testing data (Type B). The standard deviation of each uncertainty component was calculated using Equation (A5):

$$
u_{i, A}=\frac{\delta}{\sqrt{3}}
$$

where $\delta$ is the accuracy of the measurement tool.

Moreover, the repetition of the experiment reveals that another source of uncertainty exists in the results originating from any valid method for testing data:

$$
u_{i, B}=\frac{s}{\sqrt{n}}
$$

where $u_{i}$ is the standard uncertainty of the data $x_{i}, n$ is the number of the repetitions of the measurement of the parameter " $i$ ", and $s$ is the total standard deviation of the mean:

$$
s=\sqrt{\frac{\sum\left(x_{i}-\bar{x}\right)^{2}}{n-1}}
$$

where $x_{i}$ indicates each measurement and $\bar{x}$ is the mean value of the measurement of the parameter " $i$ ". Eventually, the total standard uncertainty of the measurement of the parameter " $i$ " was calculated as the following:

$$
\begin{gathered}
s=\sqrt{\frac{\sum\left(x_{i}-\bar{x}\right)^{2}}{n-1}} \\
u_{i, t o t}=\sqrt{u_{i, A^{2}+u_{i, B}{ }^{2}}}
\end{gathered}
$$

Furthermore, if a parameter was a function of several independent parameters as Equation (A9), the combined uncertainty of the parameter " $y$ " was calculated using Equation (A10).

$$
\begin{gathered}
y=f\left(x_{1}, x_{2}, \ldots, x_{n}\right) \\
u_{y, c}{ }^{2}=\sum_{i=1}^{n}\left(\frac{\partial f}{\partial x_{i}}\right)^{2} u^{2}\left(x_{i}\right)
\end{gathered}
$$

In this work, the expanded uncertainty of the combined parameter was considered by adopting a coverage factor of " $K=2$ " associated with the confidence level of $95 \%$ :

$$
U_{y}=K \cdot u_{y, c}
$$




\section{Appendix C. Geometry-Independent Correlations of CHTCs}

Single-phase:

- Ditteus-Boettler (originally introduced for single-phase turbulent flows in tubes)

$$
N u_{D}=a \cdot \operatorname{Re}_{D}^{b} \cdot \operatorname{Pr}{ }^{c}
$$

- $\quad$ Sieder-Tate (originally introduced for single-phase turbulent flows in tubes)

$$
N u_{D}=a \cdot \operatorname{Re}_{D}^{b} \cdot \operatorname{Pr}^{c}\left(\frac{\mu}{\mu_{w}}\right)^{0.14}
$$

- Bogaert-Bolcs (originally introduced for mineral oil in PHEs)

$$
N u_{D}=a \cdot \operatorname{Re}_{D}^{b} \cdot \operatorname{Pr}{ }^{\left(\frac{1}{3} e^{\left(\frac{6.4}{P r+30}\right)}\right)}\left(\frac{\mu}{\mu_{w}}\right)^{\frac{0.3}{(\operatorname{Re}+6)^{0.125}}}
$$

- Kays and Crawford (originally introduced for single-phase turbulent flows in tubes)

$$
N u_{D}=\frac{a \cdot R e_{D}{ }^{0.8} \cdot \operatorname{Pr}}{0.88+2.03\left(\operatorname{Pr}^{\frac{2}{3}}-0.78\right) R e_{D}-0.1}
$$

Condensation:

- Kuo et al. (originally introduced for R410 in PHEs)

$$
\begin{aligned}
h_{L} & =a\left(\frac{\lambda_{L}}{D_{h}}\right) \operatorname{Re}_{L}{ }^{0.78} \cdot \operatorname{Pr}_{L}{ }^{\frac{1}{3}}\left(\frac{\mu}{\mu_{w}}\right)^{0.14} \\
h_{t p} & =\left(0.25 C o^{-0.45} \cdot \operatorname{Fr}_{L}^{0.25}+75 B o^{0.75}\right)
\end{aligned}
$$

where $\mathrm{Co}, \mathrm{Fr}_{L}$, and $\mathrm{Bo}$ are convection number, Froud number, and boiling number, respectively represented in the following equations:

$$
\begin{gathered}
C o=\left(\frac{\rho_{g}}{\rho_{L}}\right)\left(\frac{1-x_{m}}{x_{m}}\right)^{0.8} \\
F r_{L}=\frac{G^{2}}{\rho_{L}^{2} \cdot g \cdot D_{h}} \\
B o=\frac{q}{G \cdot i_{f g}}
\end{gathered}
$$

- Claesson et al. (originally introduced for R134a in PHEs)

$$
\begin{gathered}
h_{N u}=a \cdot \lambda_{L}\left(\frac{R e \cdot \mu_{L}}{\rho_{L}\left(\rho_{L}-\rho_{g}\right) g}\right)^{\frac{-1}{3}} \\
h_{t p}=\sqrt{h_{N u^{2}}+h_{\text {Bogaert }}{ }^{2}}
\end{gathered}
$$

Boiling CHTC correlations:

- Hsieh et al. (originally introduced for R410 in PHEs)

$$
\begin{gathered}
h_{L}=0.023 \operatorname{Re}_{L}{ }^{0.8} \cdot \operatorname{Pr}^{0.4}\left(\frac{\lambda_{L}}{D_{h}}\right) \\
h_{\text {pool }}=55 P_{r}^{0.12}\left(-\ln P_{r}\right)^{-0.55} M^{-0.5} \cdot q^{0.67}
\end{gathered}
$$




$$
\begin{gathered}
E=1+24,000 B 0^{1.16}+1.37\left(\frac{1}{X_{t t}}\right)^{0.86} \\
S=\left(1+1.15 \times 10^{-6} E^{2} \cdot R e_{L}^{1.17}\right)^{-1} \\
h_{t p}=a \cdot E \cdot h_{L}+b \cdot S \cdot h_{\text {pool }}
\end{gathered}
$$

where $M, q, X_{t t}, P_{r}$ are molecular weight, heat flux, Martinelli parameter, and reduced pressure, respectively defined as the following:

$$
\begin{gathered}
X_{t t}=\left(\frac{1-x_{m}}{x_{m}}\right)^{0.9}\left(\frac{\rho_{g}}{\rho_{L}}\right)^{0.5}\left(\frac{\mu_{L}}{\mu_{g}}\right)^{0.1} \\
P_{r}=\frac{P}{P_{\text {critical }}}
\end{gathered}
$$

- Desideri et al. (originally introduced for R245fa and R1233ZD in PHEs)

$$
h_{t p}=a \cdot W e^{-0.0322}\left(\frac{\rho_{L}}{\rho_{g}}\right)^{-0.338} \operatorname{Re}_{L}^{0.451} \cdot B d^{-0.469}
$$

where $W e, B o$, and $B d$ are Weber, Boiling (Equation (A20)), and Bond numbers, respectively defined as follows:

$$
\begin{gathered}
W e=\frac{G^{2} \cdot D_{h}}{\rho_{m} \cdot \sigma} \\
B d=\frac{\left(\rho_{L}-\rho_{g}\right) g \cdot d_{h}{ }^{2}}{\sigma}
\end{gathered}
$$

where $G$ and $\sigma$ are the mass flux and the surface tension, respectively.

- Yan et al. (originally introduced for R134a in PHEs)

$$
\begin{gathered}
N u_{t p}=a \cdot \operatorname{Re}_{L}{ }^{0.5} \cdot \operatorname{Pr}_{L}{ }^{1 / 3} \cdot B o_{e q}{ }^{0.3} \frac{G_{e q}}{G} \\
G_{e q}=G\left[\left(1-x_{m}\right)+x_{m}\left(\frac{\rho_{L}}{\rho_{g}}\right)^{0.5}\right] \\
B o_{e q}=\frac{q}{G_{e q} \cdot i_{f g}}
\end{gathered}
$$

Table A1. The calculated empirical coefficients of the hydraulic model of the PHEs of the ORC system.

\begin{tabular}{ccc}
\hline $\begin{array}{c}\text { The Empirical Coefficient in } \\
\text { Equation (32) }\end{array}$ & Evaporator & Condenser \\
\hline $\mathrm{a}$ & 9772.82 & $14,660.75$ \\
\hline
\end{tabular}

Table A2. The calculated empirical coefficients of the thermal model of the condenser.

\begin{tabular}{ccccc}
\hline $\begin{array}{c}\text { Water } \\
\text { Single-Phase in } \\
\text { Equation (A15) }\end{array}$ & $\begin{array}{c}\text { Liquid } \\
\text { Single-Phase, } \\
\text { R134a in } \\
\text { Equation (A15) }\end{array}$ & $\begin{array}{c}\text { Gas } \\
\text { Single-Phase, } \\
\text { R134a in } \\
\text { Equation (A15) }\end{array}$ & $\begin{array}{c}\text { Condensing } \\
\text { R134a in } \\
\text { Equation (A21) }\end{array}$ \\
\hline$a$ & 0.191 & 0.568 & 0.067 & 58.550 \\
\hline
\end{tabular}


Table A3. The calculated empirical coefficients of the thermal model of the evaporator.

\begin{tabular}{ccccc}
\hline & $\begin{array}{c}\text { Oil } \\
\text { Single-Phase in } \\
\text { Equation (A14) }\end{array}$ & $\begin{array}{c}\text { Single-Phase, } \\
\text { R134a in } \\
\text { Equation (A15) }\end{array}$ & $\begin{array}{c}\text { Single-Phase, } \\
\text { R134a in } \\
\text { Equation (A15) }\end{array}$ & $\begin{array}{c}\text { Boiling R134a in } \\
\text { Equation (A33) }\end{array}$ \\
\hline$a$ & 0.34641 & 0.023 & 0.023 & $f\left(R e_{\text {oil }}, P r_{\text {oil }}, R e_{\text {ref }}, P r_{\text {ref }}\right)$ \\
\hline$b$ & 0.6636 & n.a. & n.a. & n.a. \\
\hline
\end{tabular}

\section{References}

1. Jouhara, H.; Khordehgah, N.; Almahmoud, S.; Delpech, B.; Chauhan, A.; Tassou, S.A. Waste heat recovery technologies and applications. Therm. Sci. Eng. Prog. 2018, 6, 268-289. [CrossRef]

2. Li, J.; Ge, Z.; Duan, Y.; Yang, Z.; Liu, Q. Parametric optimization and thermodynamic performance comparison of single-pressure and dual-pressure evaporation organic Rankine cycles. Appl. Energy 2018, 217, 409-421. [CrossRef]

3. Mahmoudi, A.; Fazli, M.; Morad, M.R. A recent review of waste heat recovery by Organic Rankine Cycle. Appl. Therm. Eng. 2018, 143, 660-675. [CrossRef]

4. Park, B.S.; Usman, M.; Imran, M.; Pesyridis, A. Review of Organic Rankine Cycle experimental data trends. Energy Convers. Manag. 2018, 173, 679-691. [CrossRef]

5. Wang, H.; Peterson, R.B.; Herron, T. Experimental performance of a compliant scroll expander for an organic Rankine cycle. Proc. Inst. Mech. Eng. Part A J. Power Energy 2009, 223, 863-872. [CrossRef]

6. Martin, A.; Romy, R.; Agustina, D.; Ibra, A.M. Experimental study of an organic rankine cycle system using r134a as working fluid with helical evaporator and condenser. In Proceedings of the IOP Conference Series: Materials Science and Engineering, Bali, Indonesia, 24-25 October 2018; Volume 539, p. 012026.

7. $\mathrm{Mu}, \mathrm{Y}$;; Zhang, Y.; Deng, N.; Nie, J. Experimental Study of a Low-Temperature Power Generation System in an Organic Rankine Cycle. J. Energy Eng. 2015, 141, 04014017. [CrossRef]

8. Dumont, O.; Quoilin, S.; Lemort, V. Experimental investigation of a reversible heat pump/organic Rankine cycle unit designed to be coupled with a passive house to get a Net Zero Energy Building. Int. J. Refrig. 2015, 54, 190-203. [CrossRef]

9. Woodland, B.J.; Braun, J.E.; Groll, E.A.; Horton, W.T. Experimental Testing of an Organic Rankine Cycle with Scroll-type Expander. In Proceedings of the International Refrigeration and Air Conditioning Conference, West Lafayette, IN, USA, 16-19 July 2012.

10. Ziviani, D.; James, N.A.; Accorsi, F.A.; Braun, J.E.; Groll, E.A. Experimental and numerical analyses of a 5 kWe oil-free open-drive scroll expander for small-scale organic Rankine cycle (ORC) applications. Appl. Energy 2018, 230, 1140-1156. [CrossRef]

11. Landelle, A.; Tauveron, N.; Revellin, R.; Haberschill, P.; Colasson, S.; Roussel, V. Performance investigation of reciprocating pump running with organic fluid for organic Rankine cycle. Appl. Therm. Eng. 2017, 113, 962-969. [CrossRef]

12. Borsukiewicz-Gozdur, A. Pumping work in the organic Rankine cycle. Appl. Therm. Eng. 2013, 51, 781-786. [CrossRef]

13. Yamada, N.; Watanabe, M.; Hoshi, A. Experiment on pumpless Rankine-type cycle with scroll expander. Energy 2013, 49, 137-145. [CrossRef]

14. Campana, C.; Cioccolanti, L.; Renzi, M.; Caresana, F. Experimental analysis of a small-scale scroll expander for low-temperature waste heat recovery in Organic Rankine Cycle. Energy 2019, 187, 115929. [CrossRef]

15. Quoilin, S.; Van Den Broek, M.; Declaye, S.; Dewallef, P.; Lemort, V. Techno-economic survey of organic rankine cycle (ORC) systems. Renew. Sustain. Energy Rev. 2013, 22, 168-186. [CrossRef]

16. Chang, J.C.; Hung, T.C.; He, Y.L.; Zhang, W. Experimental study on low-temperature organic Rankine cycle utilizing scroll type expander. Appl. Energy 2015, 155, 150-159. [CrossRef]

17. Moradi, R.; Villarini, M.; Cioccolanti, L. Experimental modeling of a lubricated, open drive scroll expander for micro-scale organic Rankine cycle systems. Appl. Therm. Eng. 2021, in press.

18. Michael, P.W.; Khalid, H.; Wanke, T. An Investigation of External Gear Pump Efficiency and Stribeck Values. In Proceedings of the SAE Technical Papers; SAE 2012 Commercial Vehicle Engineering Congress, Illinois, IL, USA, 2 October 2012; Volume 8. Available online: https:/ / www.sae.org/publications/technical-papers/content/2012-01-2041/ (accessed on 14 August 2020).

19. Stribeck, R. Kugellager fur beliebige Belastungen. Z. Ver. Dtsch. Ing. 1901, 45, 73-79, 118-125.

20. Colebrook, C.F.; White, C.M. Experiments with Fluid Friction Factor in Roughened Pipes. Available online: https://www.scirp. org/(S(lz5mqp453edsnp55rrgjct55))/reference/ReferencesPapers.aspx?ReferenceID=1764185 (accessed on 14 August 2020).

21. Bogaert, R.; Böles, A. Global performance of a prototype brazed plate heat exchanger in a large reynolds number range. Exp. Heat Transf. 1995, 8, 293-311. [CrossRef]

22. Shah, R.K.; Focke, W.W. Plate heat exchangers and their design theory. Heat Transf. Equip. Des. 1988, 227-254.

23. Desideri, A.; Zhang, J.; Kærn, M.R.; Ommen, T.S.; Wronski, J.; Lemort, V.; Haglind, F. An experimental analysis of flow boiling and pressure drop in a brazed plate heat exchanger for organic Rankine cycle power systems. Int. J. Heat Mass Transf. 2017, 113, 6-21. [CrossRef] 
24. Dittus, F.W.; Boelter, L.M.K. Heat transfer in automobile radiators of the tubular type. Univ. Calif. Publ. Eng. Repr. Int. Commun. Heat Mass 1930, 12, 443-461. [CrossRef]

25. Sieder, E.N.; Tate, G.E. Heat Transfer and Pressure Drop of Liquids in Tubes. Ind. Eng. Chem. 1936, 28, 1429-1435. [CrossRef]

26. Kays, W.M.M.; Crawford, M.E. Convective Heat and Mass Transfer, 3rd ed.; McGraw-Hill Series in Mechanical Engineering: New York, NY, USA, 1993.

27. Claesson, J. Thermal and Hydraulic Performance of Compact Brazed Plate Heat Exchangers Operating as Evaporators in domestic Heat Pumps. Ph.D. Thesis, Department of Energy and Technology, Royal Institute of Technology, KTH, Stockholm, Sweden, 2004.

28. Claesson, J. Performance of compact brazed plate heat exchanger operating as condenser in domestic heat pump system: An experimental investigation. In Proceedings of the 8th IEA Heat Pump Conference, International Energy Agency Heat Pump Conference: Global Advances in Heat Pump Technology, Applications, and Market, Jeju-si, Korea, 26-29 April 2005.

29. Kuo, W.S.; Lie, Y.M.; Hsieh, Y.Y.; Lin, T.F. Condensation heat transfer and pressure drop of refrigerant R-410A flow in a vertical plate heat exchanger. Int. J. Heat Mass Transf. 2005, 48, 5205-5220. [CrossRef]

30. Hsieh, Y.Y.; Lin, T.F. Evaporation heat transfer and pressure drop of refrigerant R-410A flow in a vertical plate heat exchanger. J. Heat Transfer 2003, 125, 852-857. [CrossRef]

31. Yan, Y.Y.; Lin, T.F. Evaporation heat transfer and pressure drop of refrigerant r-134a in a plate heat exchanger. J. Heat Transf. 1999, 121, 118-127. [CrossRef]

32. Yu, J.; Zhang, T.; Qian, J. Electrical Motor Products: International Energy-Efficiency Standards and Testing Methods; Woodhead Publishing Limited: Cambridge, UK, 2011; ISBN 9780857090775. 